\title{
Association between epilepsy and challenging behaviour in adults with intellectual disabilities: systematic review and meta-analysis
}

\author{
Shoumitro Deb, Basma Akrout Brizard and Bharati Limbu
}

\section{Background}

Previous systematic reviews showed no significant association between epilepsy and challenging behaviours in adults with intellectual disabilities.

\section{Aims}

To identify whether there is an association between epilepsy and challenging behaviour in adults with intellectual disabilities by carrying out a systematic review of published data. PROSPERO registration number: CRD42020178092.

\section{Method}

We searched five databases and hand-searched six journals. Two authors independently screened titles, abstracts and full articles using a standardised eligibility checklist. Several metaanalyses were carried out.

\section{Results}

The narrative analysis of data from 34 included articles (14 168 adults with intellectual disabilities, 4781 of whom also had epilepsy) showed no significant association between epilepsy and challenging behaviour. Meta-analysis was possible on data from 16 controlled studies. This showed no significant intergroup difference but after sensitivity analysis meta-analysis of 10 studies showed a significantly higher rate of overall challenging behaviour in the epilepsy group (effect size: 0.16) compared with the non-epilepsy group. Aggression and self-injurious behaviour both showed a statistically significant higher rate in the epilepsy group, with very small effect sizes (0.16 and 0.28 respectively). No significant intergroup difference was observed in the rate of stereotypy.

\section{Conclusions}

The findings are contradictory and must be interpreted with caution because of the difficulty in pooling data from varied studies, which is likely to introduce confounding. Where significant differences were found, effect sizes are small and may not be clinically significant, and there are major methodological flaws in the included studies, which should be addressed in future large-scale properly controlled studies.

\section{Keywords}

Intellectual disabilities; adults; challenging behaviour; systematic review; meta-analysis.

\section{Copyright and usage}

(C) The Author(s), 2020. Published by Cambridge University Press on behalf of the Royal College of Psychiatrists. This is an Open Access article, distributed under the terms of the Creative Commons Attribution licence (http://creativecommons.org/ licenses/by/4.0/), which permits unrestricted re-use, distribution, and reproduction in any medium, provided the original work is properly cited.
Epilepsy is common in adults with intellectual disabilities, with an average estimated point prevalence of $25 \%$, compared with $<1 \%$ in the general population who do not have intellectual disabilities. ${ }^{1}$ The rate increases with the severity of disability: $:^{2}$ around $7-15 \%$ in mild to moderate intellectual disability, $67 \%$ in severe intellectual disability and $82 \%$ in profound intellectual disability. The rate increases if the intellectual disability is associated with other neurological disorders, such as cerebral palsy. ${ }^{1}$

\section{Special issues relating to epilepsy in adults with intellectual disabilities}

Certain genetic syndromes that lead to intellectual disabilities, such as Angelman, Sturge-Weber, fragile-X/ataxia, Rett, Lesch-Nyhan, Rubinstein-Taybi, Lowe and Down syndromes and tuberous sclerosis, are commonly associated with epilepsy. ${ }^{3}$ A high proportion of people with autism spectrum disorder (22\%) also have epilepsy. ${ }^{1}$ Similarly, certain epilepsy syndromes, such as West syndrome (in infants), Lennox-Gastaut syndrome, Landau-Kleffner syndrome and Dravet syndrome, are more commonly associated with intellectual disabilities. ${ }^{4}$ Compared with the general population of adults who do not have intellectual disabilities, epilepsy among adults with intellectual disabilities is not only more prevalent, but it also often manifests as multiple seizure types, starts at an early age, is of longer duration and is resistant to anti-epileptic treatment (in over $30 \%$ in the general population, compared with over $70 \%$ in intellectual disabilities). ${ }^{5}$ Diagnosing epilepsy and seizure type can be difficult in this population, and both false-positive (stereotypy, cardiac syncope, non-epileptic attack disorder may all mimic epileptic seizure) and false-negative (difficulty diagnosing absence, focal seizures) diagnoses are possible. ${ }^{6}$ Also, these people are more prone to die from sudden unexpected death in epilepsy (SUDEP).,

\section{Relationship between epilepsy and challenging behaviour in adults with intellectual disabilities}

The relationship between epilepsy and challenging behaviour in adults with intellectual disabilities is complex. ${ }^{9}$ Challenging behaviour has been defined as 'socially unacceptable behaviour that causes distress, harm or disadvantage to the persons themselves or to other people, and usually requires some intervention'. ${ }^{10}$ Challenging behaviour is prevalent among adults with intellectual disabilities, affecting up to around $62 \% .{ }^{11-14}$ More severe forms of challenging behaviour are manifested by a lower proportion (18.7-30\%). ${ }^{13,15}$ The types of challenging behaviour include aggression, destruction of property, disruptive behaviour, self-injurious behaviour, stereotypy, and sexually inappropriate and harmful behaviours. ${ }^{14,16}$ Aggression is reported in $10-20 \%$ of adults with intellectual disabilities. $^{16,17}$ The aetiology of challenging behaviour is multifactorial, including medical, psychiatric, psychological, social and 
environmental factors. Therefore, a multiprofessional approach is required to formulate a person-centred treatment plan for this difficult-to-manage problem. ${ }^{16}$ Demographic factors such as age, gender, severity of intellectual disability, associated comorbidities (e.g. other neurodevelopmental disorders such as autism spectrum disorder, attention-deficit hyperactivity disorder), medical conditions and psychosocial factors can all affect challenging behaviour in adults with intellectual disabilities. ${ }^{14,18}$ Epilepsy is one such factor that may influence a person's behaviour.

\section{Previous systematic reviews on the subject}

Three systematic reviews looked at the association between challenging behaviour and epilepsy in people with intellectual disabilities: none of these found any association. ${ }^{19-21}$ We decided to carry out an updated systematic review, as important publications either have appeared since the last reviews or were not included in those reviews. Another reason for carrying out this review is to conduct meta-analyses that were not done in any of the previous reviews.

\section{Method}

The aim of the current systematic review and meta-analysis is to identify the rates and types of challenging behaviour in adults with intellectual disabilities who have epilepsy ('the epilepsy group') and compare them with rates and types in adults with intellectual disabilities who do not have epilepsy ('the non-epilepsy group') to determine whether epilepsy is a risk factor for developing challenging behaviour in this population.

We aimed to include studies that compared the overall rate of challenging behaviour as well as different types of challenging behaviour in adults with intellectual disabilities with and without epilepsy within the same cohort. We did not aim to include any study that involved only adults with intellectual disabilities who did not have epilepsy. We included studies that involved participants without epilepsy only where they were part of the control group and participants with epilepsy were also involved in the same study.

We also aimed to include studies that involved adults with intellectual disabilities and epilepsy but no one without epilepsy. These studies are included to assess the rate of different types of challenging behaviour according to different seizure variables.

\section{Search strategy}

We decided on our final search strategy after an initial scoping literature search. We followed PROSPERO guidelines ${ }^{22}$ and the PRISMA$\mathrm{P}$ checklist to develop our protocol and search strategy. ${ }^{23}$ Five electronic databases - Embase, PubMed/MEDLINE, PsycInfo, DARE and ASSIA (ProQuest) - were searched for relevant journal articles. Each database was searched between 1 January 1985 and 31 May 2020. In addition, we also cross-referenced pertinent reviews and articles. We hand-searched for relevant articles in the past 20 years' issues, from January 1990 to May 2020, in the following intellectual disabilities journals: (a) Journal of Intellectual Disability Research, (b) Journal of Applied Research in Intellectual Disabilities (JARID) and (c) Research in Developmental Disabilities; and the following epilepsy journals: (a) Seizure, (b) Epilepsy \& Behavior and (c) Epilepsia.

Only quantitative studies in English were searched. We excluded non-human studies, studies involving children and conference abstracts.

\section{Search terms}

The list of search terms used can be found in the supplementary material available at https://doi.org/10.1192/bjo.2020.96. Search terms were adapted from previous systematic reviews that were carried out to develop a national and an international guide for the use of psychotropic medications in the management of challenging behaviour in adults with intellectual disabilities. ${ }^{10,24}$

\section{Criteria for selecting studies}

We devised a list of eligibility criteria based on PROSPERO ${ }^{22}$ and Cochrane review guidelines ${ }^{25}$ and adapted from similar systematic reviews on psychotropic medications ${ }^{26-28}$ (supplementary Appendix 1).

\section{Types of study}

There was no restriction on the type of study design included in this review. We included both randomised and non-randomised studies; controlled and non-controlled observational or cross-sectional studies; and controlled studies with both matched and nonmatched control groups.

\section{Types of participant}

All participants had intellectual disabilities, were aged 16 years or over and displayed various types of challenging behaviour. We have only included data on challenging behaviour in this review. Data on psychiatric illness without challenging behaviour are not presented in the current paper as they will be included in a separate systematic review article.

No ethical approval was required for this study as no individual patient-related data were collected or analysed.

\section{Sample size}

Studies with fewer than 10 participants were excluded. This arbitrary cut-off was used in accordance with our previous systematic reviews. $^{10}$

\section{Secondary outcome}

The rates of different types of challenging behaviour (verbal aggression and aggression towards people or property or self, stereotypy, overactivity, temper tantrum, etc.) were compared between the epilepsy and the non-epilepsy groups. Data on subgroup comparisons according to different types of seizure, seizure frequency and different pharmacological regimes (e.g. polypharmacy versus monopharmacy of anti-epileptic medications; treatment with carbamazepine versus valproate) were collected to identify the role of different epilepsy-related factors in the development of challenging behaviour.

\section{Selection process}

After the definitive search was completed, titles were searched for key terms. Zotero reference management software ${ }^{29}$ was used to manage and record references from each database. Duplicates, non-human studies and studies involving children were identified by Zotero and removed manually (by B.A.B.). The remaining abstracts were screened independently using the pre-piloted eligibility criteria (by B.A.B. and B.L.). The two authors were masked to each other's scores. Bibliographies of potential studies were screened to identify articles that required acquisition of the full text. Discrepancies identified were reviewed and discussed between B.A.B. and B.L. to resolve any differences. The full texts were then reviewed and independently assessed for eligibility by B.A.B. and B.L. using the same eligibility checklist that was used for screening the abstracts. The selection process is shown in Fig. 1. It was not necessary for the third review author (S.D.) to arbitrate. 


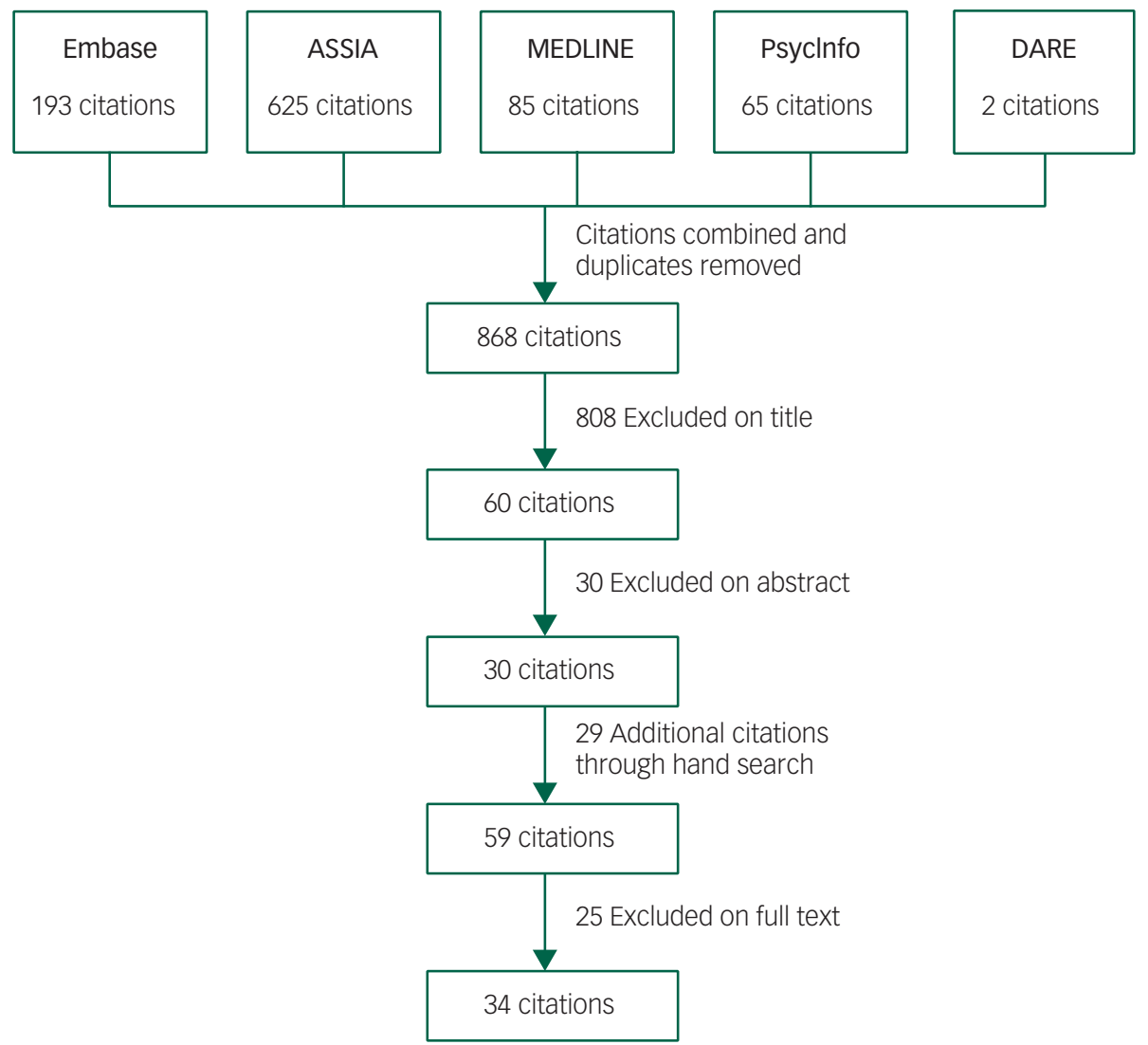

Fig. 1 The flowchart of the paper selection process.

\section{Data extraction}

Data from studies meeting eligibility criteria were extracted independently by B.A.B. and B.L. using a standardised data extraction template adapted from Cochrane review guidelines (supplementary Appendix 2). ${ }^{30}$ S.D. checked this information for accuracy. Results are reported using a narrative synthesis of information from included studies.

\section{Meta-analysis}

The meta-analysis was carried out only on controlled studies. An odds ratio was calculated for the studies that presented the proportion of participants in each group displaying challenging behaviour. A standardised mean difference was calculated for those studies that presented means and standard deviations for scores based on a behaviour rating scale in the two groups. ${ }^{31}$ To pool data, we logtransformed all data to standardised mean differences. ${ }^{31}$ RevMan $5.3^{32}$ software for Windows 10 was used for random-effects metaanalysis. Heterogeneity was tested using the $\chi^{2}$-test and $I^{2}$-statistic. Where there was substantial heterogeneity $\left(I^{2}>60 \%\right)$, a further sensitivity analysis was carried out. A final meta-analysis was carried out after removing data from the studies that produced a high heterogeneity and strong bias, to bring heterogeneity to an acceptable level $\left(I^{2}<30\right)$.

\section{Risk-of-bias assessment and confidence in cumulative estimates}

The risk of bias for the 19 controlled studies identified was assessed independently by B.A.B. and B.L. using the Cochrane risk-of-bias tool $^{33}$ and the quality of all 32 eligible studies was assessed during the data collection process using the SIGN 50 checklist. ${ }^{34}$
Publication bias was assessed using a funnel plot, and the studies included were assessed for consistency and precision. The quality of the overall systematic review was assessed using AMSTAR 2 criteria (see Appendix 3; supplementary material). ${ }^{35}$

\section{Results}

\section{Included studies}

Of the 868 articles screened, 34 papers (from 32 studies) met the eligibility criteria and were included in the systematic review (Fig. 1). A list of excluded articles with reason for exclusion is presented in supplementary Appendix 4. Two studies each published two papers on the same sample but on different outcome measures. Of the 34 papers, 19 included participants with and without epilepsy, as their authors compared the rates of challenging behaviour in these two groups to assess an association between challenging behaviour and epilepsy (Table 1). Of these, nine studies ${ }^{36-44}$ had equal numbers of participants in both groups and the groups were matched on various demographic variables. The rest $(n=$ $10)^{12,45-53}$ were prevalence studies of challenging behaviour in adults with intellectual disabilities that included a number of participants with epilepsy (around $22 \%$ of the cohort). Different variables, such as age, gender and presence/absence of epilepsy, were used to assess whether they are risk factors for developing challenging behaviour. The rates of challenging behaviour were compared on the basis of the presence or absence of epilepsy, but the epilepsy groups were not matched with the non-epilepsy groups. The rest of the studies included participants with epilepsy only, and in these the rates of challenging behaviour were compared between various types of epilepsy (e.g. frequent versus infrequent; generalised 
Table 1 Rates of challenging behaviour in adults with intellectual disabilities with and without epilepsy

\section{Study and \\ country}

matched control group

(1987), ${ }^{36}$ UK $\quad 32$ with epilepsy

Espie et al 15 with epilepsy; 15 without

(1989), ${ }^{37}$ UK epilepsy

Gillies et al

(1989), ${ }^{38}$ UK

65 with epilepsy; 65 without epilepsy

Collacott

$(1993),{ }^{39} \mathrm{UK}$

Deb (1997),

Down syndrome: 35 with

epilepsy; 68 without epilepsy

epilepsy

Matson et al 353 with epilepsy; 353 without

(1999), ${ }^{41}$ USA epilepsy

Chung \&

Cassidy

Part 2: 14 with epilepsy; 14

6-70

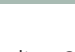

20-46

articipant age, years

DAS severity $\geq 3$

ABS-II (maladaptive behaviour), PBS Wilcoxon matched-pairs

PBS

Mean. 30.1

Under 20 to over 60

Mean: 37.8

$$
\text { epilepsy }
$$

$$
\text { without epilepsy }
$$

Matthews et al 55 with epilepsy; 55 without

(2008), ${ }^{43}$ UK

Smith \& epilepsy

Matson

(2010), ${ }^{44}$ USA

Studies with unmatched control group

Prasher 201 with Down syndrome, of

whom 32 had epilepsy

(1995), ${ }^{45}$ UK

$$
\text { whom } 32 \text { had epilepsy }
$$

Deb et al

(2001), ${ }^{12}$ UK

Espie et al

(2003), ${ }^{46}$ UK

101, including 25 with epilepsy

178 with epilepsy compared with 1022 normative non-epilepsy standardisation group

Turkistani

(2004) ${ }^{47}$ UK

108 with epilepsy; 132 without epilepsy

McGrother et

2393 , including 620 with epilepsy

177, including 53 with epilepsy

Pawar \&

Akuffo

(2008), ${ }^{49}$ UK
Mean: 35

20-77

ABS-II (maladaptive behaviour)

ANOVA

PAA (maladaptive behaviour items) Wilcoxon matched-pairs

DASH-II, ABC

signed-ranks test

ANOVA

$17-86$

$17-86$

Mean: 44.2

$16-64$

Mean: 35.5

Mean: 40.3

Over 20

Over 17
ABC subdomains

ABC total score $>45$

ASD-CA
ABS-II (maladaptive behaviour)
(compared between 12
participants with epilepsy and 47

$$
\text { without) }
$$

DAS

ABC subdomains

Parents' and carers' report of

DAS

Case notes normative data using Cronbach alpha

Univariate, multivariate Logistic regression Descriptive statistics student's $t$-test

signed-ranks test

Student's t-test

Results

No statistically significant intergroup difference in maladaptive behaviour scores (epilepsy group, mean: 21.7, s.d. $=4.5$; non-epilepsy group, mean: 20.3 , s.d. $=4.8$ )

No statistically significant intergroup difference according to the ABS-II total score (epilepsy group, mean: 75.53 , s.d. $=9.02$; non-epilepsy group, mean: 72.4, s.d. $=7.91$ ). PBS subscores and factor scores did not show any intergroup significant difference either

Statistically significant higher total PBS score in the epilepsy group compared with the control group (epilepsy group, mean: 41.99, s.d. $=24.31$; non-epilepsy group, mean: 30.2 , s.d. $=22.4, P=0.005$ )

No significant intergroup difference in total ABS-II score

No statistically significant difference in severe maladaptive behaviour between epilepsy group (58\%) and non-epilepsy group (52\%)

Epilepsy group had a statistically significant lower DASH-II total score and ABC total score compared with the non-epilepsy group. DASH-II total score (epilepsy group, mean: 11, s.d. = 10.58; non-epilepsy group, mean: 15.2, s.d. $=11.22, P<0.001$ ). ABC total score (epilepsy group, mean: 12.4, s.d. $=16.43$; non-epilepsy group, mean: 21.37 , s.d. $=21.54$ $P<0.001)$

Epilepsy group had a statistically significant higher ABC-Irritability score (mean: 17.86) compared with the non-epilepsy group (mean: 8.2) ( $t=2.99, P<0.01)$. No significant intergroup difference was found in any other $\mathrm{ABC}$ subscores

No significant intergroup difference (epilepsy group: $23.6 \%$ v. non-epilepsy group: $20 \%$.

No statistically significant intergroup difference in conduct disorder score (epilepsy group, mean: 1.4, s.d. = 1.58; non-epilepsy group, mean: 1.16, s.d. $=2.19)(F=1.22 ; p=0.31)$

No significant intergroup difference in total ABS-II score (epilepsy group, mean: 18.27 , s.d. $=9.10$; non-epilepsy group, mean: 15.84 , s.d. $=10.40$ $(t=0.16))$

No significant intergroup difference in the rate of overall maladaptive behaviour ( $76 \%$ of epilepsy group; $55 \%$ of non-epilepsy group)

All ABC subdomain scores in the epilepsy group were consistently 4 points lower (equivalent to 0.5 s.d.) compared with the normative data. All scores were consistently below 50th percentile. ABC-Irritability sample mean: 6.54 , s.d. $=7.6 \mathrm{~V}$. normative data mean 10.54 , s.d. $=9.8$

No significant difference in the rate of disturbed behaviour between epilepsy (27.7\%) and non-epilepsy (37.9\%) groups
People with epilepsy had significantly higher total DAS score than those without epilepsy $(54.2$ v. $42 \%, \mathrm{OR}=1.6, P<0.0001)$

Lower rates of challenging behaviour in the epilepsy group (59\%) compared with the non-epilepsy group (70\%) 


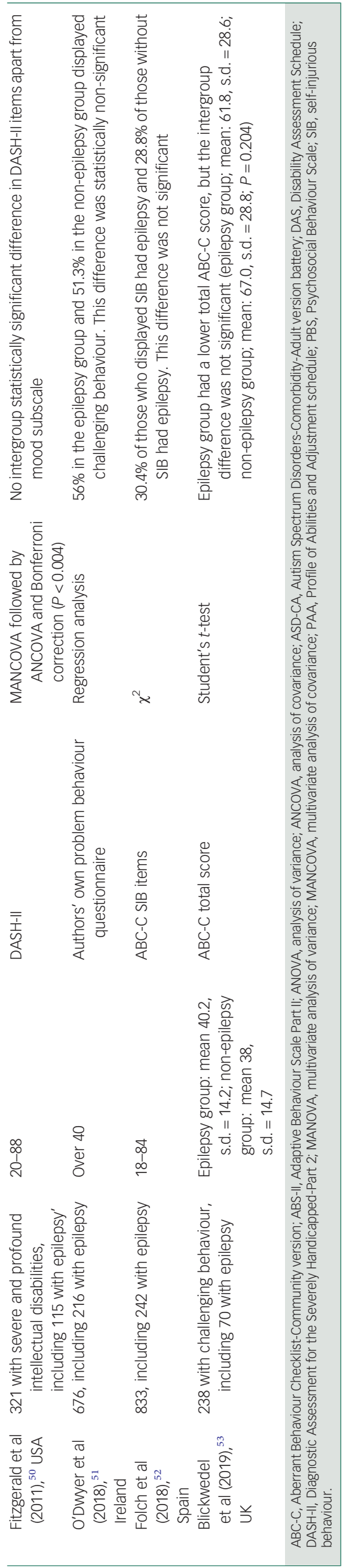

versus focal seizures). Table 2 compares the rates of different types of challenging behaviour (e.g. aggression, self-injurious behaviour) between the epilepsy and the non-epilepsy groups. Table 3 presents data on participants with epilepsy only and compares rates of challenging behaviour according to various epilepsy variables. Most studies were carried out in the UK $(n=24)$, some in the USA $(n=4)$ and one each in Ireland, Sweden, The Netherlands and Spain. In total, data on 14168 adults with intellectual disabilities are presented (4781 with epilepsy and 9387 without epilepsy).

\section{Diagnosis}

Challenging behaviour is defined using a variety of methods in different studies. Five studies ${ }^{49,54-57}$ collected data retrospectively from participants' case notes and did not use any validated measures. One study ${ }^{47}$ collected information on challenging behaviour from parents' and carers' reports and one study ${ }^{51}$ used its own questionnaire, for which no validation data are provided. Among the studies that used validated questionnaires, five $e^{12,36,48,58,59}$ used challenging behaviour items from the Disability Assessment Schedule (DAS) ${ }^{60}$ and another three ${ }^{40,61,62}$ used DAS challenging behaviour items from the Profile of Abilities and Adjustment schedule (PAA). ${ }^{61,63}$ Three studies ${ }^{37,39,45}$ used the Adaptive Behaviour Scale Part II (ABS-II), ${ }^{64}$ which scores maladaptive behaviours. Two studies ${ }^{41,50}$ used the Diagnostic Assessment for the Severely Handicapped Part 2 (DASH-II). ${ }^{65}$ Two studies ${ }^{43,53}$ used the Aberrant Behaviour Checklist-Community version (ABC-C) total score, ${ }^{66}$ and another four ${ }^{42,46,52,67}$ used ABC-C subdomain scores. ${ }^{68}$ Three studies $^{37,38,69}$ used the Psychosocial Behaviour Scale (PBS). ${ }^{70}$ The Behaviour Problem Inventory $(\mathrm{BPI})^{71}$ was used in two studies ${ }^{12,72}$ to rate challenging behaviour. One study each used the Diagnostic Criteria-Learning Disability (DC-LD) ${ }^{73-75}$ Autism Spectrum Disorders-Comorbidity-Adult version (ASD-CA) 44,76 $^{\text {and Autism }}$ Spectrum Disorders-Behaviour Problems for Adults (ASD$\mathrm{BPA})^{77,78}$ respectively.

\section{Statistical methods used}

Where a standardised scale was used to measure challenging behaviours, some studies compared means and standard deviations for the two groups, whereas others used an arbitrary cut-off score to compare participants in the two groups. ${ }^{79}$ Various statistical methods were used, including $\chi^{2}$, regression analysis, univariate and multivariate regression analyses, the Wilcoxon matched-pairs signed-ranks test and Student's $t$-test.

\section{Outcome (narrative synthesis)}

\section{The overall rate of challenging behaviour}

Of the total 19 controlled studies, $13^{12,36,37,39,40,43-45,47,50-53}$ did not show any significant intergroup difference in the overall rate of challenging behaviour, three ${ }^{38,42,48}$ showed a significantly higher rate of challenging behaviour in the epilepsy group and three ${ }^{41,46,49}$ showed a higher overall rate of challenging behaviour in the non-epilepsy group (Table 1). Of these three, one ${ }^{41}$ was at a significant level and the level of significance for other two ${ }^{46,49}$ is not known.

\section{Rates of different types of challenging behaviour}

Table 2 shows the rates of different types of challenging behaviour in the epilepsy and the non-epilepsy groups. For aggression, nine studies ${ }^{12,13,37,48,49,53,54,74,77}$ showed no significant intergroup difference. According to two studies ${ }^{38,59}$ the epilepsy group showed a statistically significant higher rate of aggression compared with the non-epilepsy group. In one study ${ }^{67}$ aggression was less common in the epilepsy group. For self-injurious behaviour, six studies $^{12,13,48,58,73,77}$ showed no significant intergroup difference 
Table 2 Types of challenging behaviour in adults with intellectual disabilities with and without epilepsy

\begin{tabular}{|c|c|c|c|c|c|c|}
\hline $\begin{array}{l}\text { Study and } \\
\text { country }\end{array}$ & Study design & Sample, control group & Age, years & Measures used & Statistical analysis & Results \\
\hline $\begin{array}{l}\text { Gillies et al } \\
\quad(1989),{ }^{38} \text { UK }\end{array}$ & $\begin{array}{l}\text { Matched } \\
\text { controlled } \\
\text { study }\end{array}$ & $\begin{array}{l}65 \text { with epilepsy; } 65 \text { without } \\
\text { epilepsy }\end{array}$ & Mean: 30.1 & PBS & Student $t$-test & $\begin{array}{l}\text { Significantly higher rates of physical aggression in the epilepsy group } \\
\text { compared with the control group }(t=2.02 \text {, d.f. }=40, P<0.05)\end{array}$ \\
\hline $\begin{array}{l}\text { Espie et al } \\
\qquad(1989),{ }^{37} \text { UK }\end{array}$ & $\begin{array}{l}\text { Matched } \\
\text { controlled } \\
\text { study }\end{array}$ & $\begin{array}{l}15 \text { with epilepsy; } 15 \text { without } \\
\text { epilepsy }\end{array}$ & $20-46$ & $\begin{array}{l}\text { ABS-II (maladaptive } \\
\text { behaviour) }\end{array}$ & $\begin{array}{l}\text { Wilcoxon matched- } \\
\text { pairs signed-ranks } \\
\text { test }\end{array}$ & $\begin{array}{l}\text { ABS-II SIB score was significantly lower (mean: } 76.40, \text { s.d. }=10.12, v \text {. mean: } \\
\text { 86.20, s.d. }=11.35, F=-2.49, P=0.006 \text { ) but aggressive and destructiveness } \\
\text { scores were similar (mean: } 74.26, \text { s.d. }=19.80, v \text {. mean: } 74.33, \text { s.d. }=20.76, F \\
=-0.16, P=0.438 \text { ) in the epilepsy group compared with the non-epilepsy } \\
\text { group }\end{array}$ \\
\hline $\begin{array}{l}\text { Creaby et al } \\
\qquad(1993)^{54} \text { UK }\end{array}$ & $\begin{array}{l}\text { Unmatched } \\
\text { controlled } \\
\text { study }\end{array}$ & $\begin{array}{l}230 \text { with severe intellectual } \\
\text { disability, including } 131 \\
\text { epilepsy }\end{array}$ & $\begin{array}{l}\text { Mean: epilepsy 38.8; non- } \\
\text { epilepsy } 40.3\end{array}$ & $\begin{array}{l}\text { Information gathered } \\
\text { from case notes using } \\
\text { a checklist }\end{array}$ & $\chi^{2}$ & $\begin{array}{l}\text { 37.4\% of epilepsy and } 36.3 \% \text { of non-epilepsy groups showed paroxysmal } \\
\text { aggression. This difference was not statistically significant }\end{array}$ \\
\hline $\begin{array}{l}\text { Collacott et al } \\
\qquad(1998),{ }^{58} \text { UK }\end{array}$ & $\begin{array}{l}\text { Cross-sectional } \\
\text { study }\end{array}$ & $\begin{array}{l}\text { 2101, of whom } 372 \text { showed } \\
\text { SIB. Number with } \\
\text { epilepsy is not known }\end{array}$ & Mean: 33.56 & DAS & Mann-Whitney & $\begin{array}{l}\text { No difference in the prevalence of epilepsy between those with and without SIB } \\
\left.\qquad \chi^{2}=2.36, \text { d.f. }=1, P=0.13\right)\end{array}$ \\
\hline $\begin{array}{l}\text { Andrews et al } \\
\qquad(1999){ }_{1}^{67} \text { UK }\end{array}$ & $\begin{array}{l}\text { Cross-sectional } \\
\text { study }\end{array}$ & 115 with epilepsy & $18-93$ & ABC subdomain scores & Mann-Whitney & $\begin{array}{l}\text { Scores for all } 5 \text { ABC subdomains (irritability, lethargy, stereotype, hyperactivity, } \\
\text { inappropriate speech) are lower than the normative data when matched for } \\
\text { intellectual disability level }\end{array}$ \\
\hline $\begin{array}{l}\text { Deb et al } \\
\qquad(2001),{ }_{1}^{12} \text { UK }\end{array}$ & $\begin{array}{l}\text { Observational } \\
\text { study }\end{array}$ & $\begin{array}{l}\text { 101, including } 25 \text { with } \\
\text { epilepsy }\end{array}$ & $16-64$ & DAS & Regression analysis & 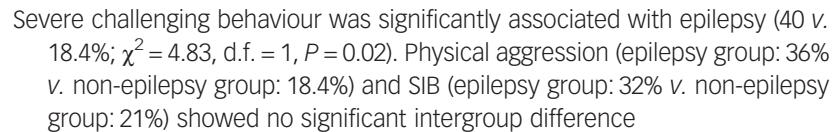 \\
\hline $\begin{array}{l}\text { McGrother et al } \\
(2006),{ }^{48} \text { UK }\end{array}$ & $\begin{array}{l}\text { Population-based } \\
\text { study }\end{array}$ & $\begin{array}{l}\text { 2393, including } 620 \text { with } \\
\text { epilepsy }\end{array}$ & Over 20 & DAS & $\begin{array}{l}\text { Logistic regression } \\
\text { with Bonferroni } \\
\text { correction }\end{array}$ & 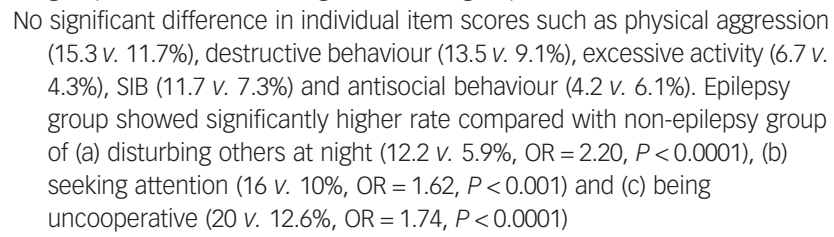 \\
\hline $\begin{array}{l}\text { Tyrer et al } \\
\qquad(2006),{ }^{59} \text { UK }\end{array}$ & $\begin{array}{l}\text { Cross-sectional } \\
\text { design }\end{array}$ & $\begin{array}{l}\text { 3062, including } 812 \text { with } \\
\text { epilepsy }\end{array}$ & 19-92 & DAS & Logistic regression & $\begin{array}{l}19 \% \text { of people with epilepsy showed aggressive behaviour compared with } 13 \% \\
\text { without epilepsy }(\mathrm{OR}=1.55, P<0.001) \text {. Physical aggression to others was } \\
\text { not significantly associated with epilepsy }(\mathrm{OR}=0.95, P=0.67)\end{array}$ \\
\hline $\begin{array}{l}\text { Pawar \& Akuffo } \\
\quad(2008),{ }^{49} \mathrm{UK}\end{array}$ & $\begin{array}{l}\text { Observational } \\
\text { survey }\end{array}$ & $\begin{array}{l}\text { 177, including } 53 \text { with } \\
\text { epilepsy }\end{array}$ & Over 17 & Case notes & Descriptive statistics & $\begin{array}{l}\text { Verbal aggression: } 11 \% \text { in epilepsy group v. } 35 \% \text { in non-epilepsy group. Physical } \\
\text { assault: } 35 \% \text { in the epilepsy group v. } 34 \% \text { in non-epilepsy group. } \\
\text { Inappropriate sexual behaviour: } 2 \% \text { in epilepsy group v. } 6 \% \text { in non-epilepsy } \\
\text { group }\end{array}$ \\
\hline $\begin{array}{l}\text { Cooper et al } \\
\quad(2009))^{73} \mathrm{UK}\end{array}$ & $\begin{array}{l}\text { Prospective } \\
\quad \text { cohort study }\end{array}$ & $\begin{array}{l}\text { 1023, including } 349 \text { with } \\
\text { epilepsy }\end{array}$ & Over 16 & DC-LD & $\begin{array}{l}\text { Univariate, } \\
\text { multivariate } \\
\text { regression } \\
\text { analysis }\end{array}$ & $\begin{array}{l}\text { SIB: } 7.2 \% \text { in epilepsy group } v \text {. } 3.5 \% \text { in non-epilepsy group }(P=0.009) \text {. At } \\
\text { multivariate analysis this difference was not significant }\end{array}$ \\
\hline $\begin{array}{l}\text { Cooper et al } \\
\quad(2009))^{74} \mathrm{UK}\end{array}$ & $\begin{array}{l}\text { Prospective } \\
\text { cohort study }\end{array}$ & $\begin{array}{l}\text { 1023, including } 349 \text { with } \\
\text { epilepsy }\end{array}$ & Over 16 & DC-LD & $\begin{array}{l}\text { Univariate, regression } \\
\text { analysis }\end{array}$ & $\begin{array}{l}\text { No statistically significant intergroup difference in aggressive behaviour } \\
\text { between epilepsy (12\%) and non-epilepsy (8.4\%) groups }\end{array}$ \\
\hline $\begin{array}{l}\text { Smith \& Matson } \\
(2010),{ }^{77} \text { USA }\end{array}$ & $\begin{array}{l}\text { Observational } \\
\text { study }\end{array}$ & $\begin{array}{l}\text { 100, including } 25 \text { with } \\
\text { epilepsy }\end{array}$ & $29-76$ & ASD-BPA & MANOVA and ANOVA & $\begin{array}{l}\text { No significant intergroup (epilepsy } v \text {. non-epilepsy) difference in aggressive } \\
\text { behaviour (mean: } 0.68 \text { v. } 0.56 \text { ), stereotypy (mean: } 0.68 \text { v. } 0.52 \text { ), SIB (mean: } \\
0.2 \text { v. 0.08) and disruptive behaviour (mean: } 0.2 v .0 .44 \text { ) }\end{array}$ \\
\hline $\begin{array}{l}\text { Lundqvist } \\
\qquad(2013)_{1}^{13} \\
\text { Sweden }\end{array}$ & $\begin{array}{l}\text { Observational } \\
\text { study }\end{array}$ & $\begin{array}{l}\text { 915, including } 124 \text { with } \\
\text { epilepsy }\end{array}$ & $18-87$ & $\begin{array}{l}\text { BPI with additional } \\
\text { questions }\end{array}$ & $\begin{array}{l}\text { Univariate and } \\
\text { multivariate } \\
\text { regression } \\
\text { analysis }\end{array}$ & $\begin{array}{l}\text { SIB: } 45.2 \% \text { in epilepsy group v. } 28.7 \% \text { in non-epilepsy group; stereotypical } \\
\text { behaviour: } 50 \text { v. } 39.9 \% \text {; aggressive/destructive behaviour: } 37.1 \text { v. } 34 \% \text {. None } \\
\text { of these differences were statistically significant after multivariate } \\
\text { regression analysis }\end{array}$ \\
\hline
\end{tabular}




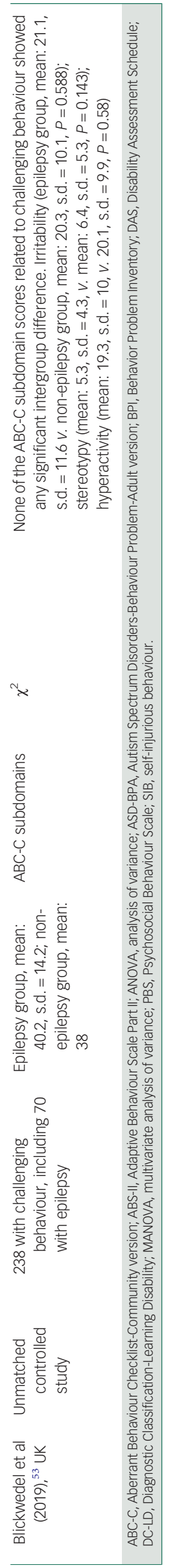

and one study ${ }^{37}$ showed significantly less self-injurious behaviour in the epilepsy group compared with the non-epilepsy group. For aggression to property or destructiveness, three studies ${ }^{13,37,48}$ showed no significant intergroup difference and no study showed a higher rate in the epilepsy group compared with the non-epilepsy group. One study ${ }^{48}$ showed a significantly higher rate of behaviours such as disturbing others at night, seeking attention and being uncooperative in the epilepsy group compared with the non-epilepsy group. Rates of behaviours such as stereotypy, inappropriate sexual behaviour, irritability, hyperactivity, verbal aggression, antisocial behaviours and lethargy. were reported in a very small number of studies showing equivocal findings.

\section{Association between challenging behaviour and epilepsy-related variables}

Table 3 presents data on the rate of challenging behaviour according to different epilepsy variables. For example, in three studies ${ }^{54,61,72}$ a significantly higher rate is reported among those with generalised seizures as opposed to focal seizures but in one study ${ }^{67}$ the intergroup difference was not significant. Similarly, three studies ${ }^{38,61,72}$ showed a higher rate of challenging behaviour among those who presented with frequent seizures as opposed to those who had less frequent seizures. However, in five studies ${ }^{37,47,54,55,58}$ no such significant intergroup difference was found. In one study ${ }^{61}$ those who showed generalised epileptiform changes on electroencephalograms (EEGs) showed a significantly higher rate of challenging behaviour compared with those whose EEGs showed focal epileptiform changes.

\section{Association between challenging behaviour and anti-epileptic medication-related variables}

Three studies ${ }^{37,61,69}$ showed a significantly higher rate of challenging behaviour among those who received multiple anti-epileptic medications (polypharmacy group) compared with those who received single anti-epileptic medication (monopharmacy group). However, no such significant intergroup difference was found in five studies. ${ }^{37,47,53,54,56}$ Interestingly, two studies ${ }^{54,72}$ reported a higher rate of challenging behaviour in the monopharmacy group than in the polypharmacy group, and in one of these studies this intergroup difference was significant. ${ }^{72}$ Only one study reported the rate of challenging behaviour in various monopharmacy groups (phenytoin, sodium valproate, carbamazepine and lamotrigine monopharmacy) but it made no intergroup comparison. $^{56}$

\section{Meta-analysis}

Of the 19 controlled studies, data were available for meta-analysis from 16. Pooled data from the 16 studies using a random-effects meta-analysis of standardised mean differences showed no significant intergroup difference but the heterogeneity among studies was very high $\left(I^{2}=88 \%\right)$ (Fig. 2$)$. After sensitivity analysis we removed data from studies that produced the highest level of heterogeneity and had a high risk of bias according to the Cochrane riskof-bias tool. The final meta-analysis, using a random-effects model, of pooled data from the remaining 10 studies showed a statistically significant higher rate of overall challenging behaviour in the epilepsy group compared with the non-epilepsy group, with a very small effect size of 0.16 . The heterogeneity among studies came down to an acceptable level $\left(I^{2}=18 \%\right)$ (Fig. 3). To study specific types of challenging behaviour, we conducted meta-analyses of pooled data on aggression scores from nine studies (Fig. 4), on self-injurious behaviour from six (Fig. 5) and on stereotypy from three (Fig. 6). The aggression meta-analysis showed a significantly higher rate in the epilepsy group compared with the non-epilepsy 
Table 3 Challenging behaviours in adults with intellectual disabilities according to different epilepsy variables

\begin{tabular}{|c|c|c|c|c|c|c|}
\hline Reference & Study design & Sample, control group & Age, years & Measures used & Statistical analysis & Results \\
\hline $\begin{array}{l}\text { Gillies et al } \\
\quad(1989),{ }^{38} \text { UK }\end{array}$ & $\begin{array}{l}\text { Unmatched } \\
\text { controlled } \\
\text { study }\end{array}$ & $\begin{array}{l}21 \text { with high frequency of seizures; } 44 \text { with } \\
\text { low frequency of seizures }\end{array}$ & Mean: 30.1 & PBS & Student's t-test & $\begin{array}{l}\text { Statistically significant higher total PBS score in the high seizure- } \\
\text { frequency group }(n=21 \text { ) (mean: } 54.05, \text { s.d. }=24.57, t=2.92 \text { ) } \\
\text { compared with the low seizure-frequency group }(n=44) \text { (mean: } \\
\text { 36.23, s.d. }=22.22, t=2.92, P=0.005 \text { ) }\end{array}$ \\
\hline $\begin{array}{l}\text { Espie et al } \\
\quad(1989),{ }^{37} \text { UK }\end{array}$ & $\begin{array}{l}\text { Matched } \\
\text { controlled } \\
\text { study }\end{array}$ & 15 with epilepsy; 15 without epilepsy & $20-46$ & $\begin{array}{r}\text { ABS-II (maladaptive } \\
\text { behaviour), PBS }\end{array}$ & ANCOVA & 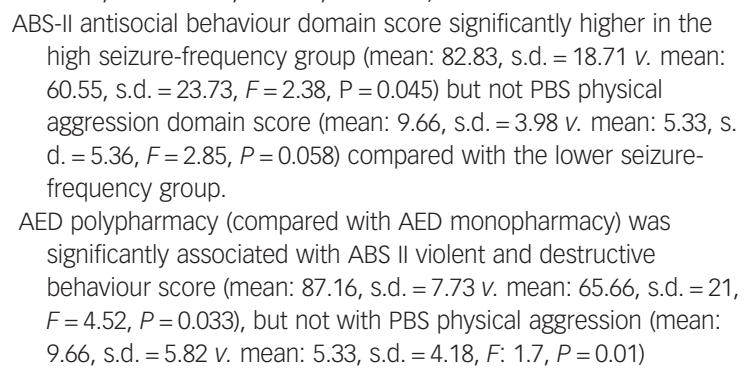 \\
\hline $\begin{array}{l}\text { Espie et al } \\
\qquad(1990){ }_{1}^{69} \text { UK }\end{array}$ & $\begin{array}{l}\text { Observational } \\
\text { study }\end{array}$ & 65 with epilepsy & Mean: 30.33 & PBS total score & $\begin{array}{l}\text { Rank sum test (non- } \\
\text { parametric } \\
\text { comparison of } \\
\text { median values) }\end{array}$ & $\begin{array}{l}\text { Global behaviour problems (PBS total score) were greater in the AED } \\
\text { polypharmacy group (mean: } 52.3, \text { s.d. }=23.9 \text { ) than in the AED } \\
\text { monopharmacy group (mean: } 33.5 ; \text { s.d. }=19.7)(P<0.001 \text { ) }\end{array}$ \\
\hline $\begin{array}{l}\text { Deb \& Hunter } \\
\quad(1991),{ }_{1}^{11} \text { UK }\end{array}$ & $\begin{array}{l}\text { Matched } \\
\text { controlled } \\
\text { study }\end{array}$ & 150 with epilepsy; 150 without epilepsy & $20-77$ & $\begin{array}{l}\text { PAA (maladaptive } \\
\text { behaviour items) }\end{array}$ & Wilcoxon & $\begin{array}{l}\text { Among in-patients: the epilepsy group showed significantly (a) less } \\
\text { aggression in the single seizure group and less irritability in the EEG } \\
\text { group who had only slow background wave compared with } \\
\text { epileptiform activities, (b) more irritability in the EEG group who had } \\
\text { generalised epileptiform activity, (c) less aggression in the AED } \\
\text { monopharmacy group and the carbamazepine monopharmacy } \\
\text { group. Among community patients: SIB was associated with } \\
\text { multiple and frequent seizures }\end{array}$ \\
\hline $\begin{array}{l}\text { Creaby et al } \\
\quad(1993),{ }^{54} \text { UK }\end{array}$ & $\begin{array}{l}\text { Observational } \\
\text { study }\end{array}$ & $\begin{array}{l}131 \text { with severe intellectual disability and } \\
\text { epilepsy }\end{array}$ & Mean: 40 & Case notes & $\chi^{2}$ & $\begin{array}{l}\text { 41.7\% with generalised seizures and } 17.4 \% \text { with partial seizures } \\
\left.\text { showed aggression ( } \chi^{2}=4.74, \text { d.f. }=1, P=0.029\right) ; 32 \% \text { of those who } \\
\text { received polypharmacy and } 41.3 \% \text { of those who received AED } \\
\text { monopharmacy showed aggression (this difference was non- } \\
\text { significant); } 35 \% \text { with severe (very frequent) seizures, } 41 \% \text { with } \\
\text { moderately frequent seizures, and } 40 \% \text { with mild (infrequent) } \\
\text { seizures showed aggression (these differences were not } \\
\text { significant) }\end{array}$ \\
\hline Deb (1995), ${ }^{62}$ UK & $\begin{array}{l}\text { Observational } \\
\text { study }\end{array}$ & 100 with epilepsy & $20-77$ & $\begin{array}{l}\text { PAA (maladaptive } \\
\text { behaviour items) }\end{array}$ & $\chi^{2}$ & $\begin{array}{l}58 \% \text { of those with generalised epileptiform changes in EEG as opposed } \\
\text { to } 50 \% \text { of those with focal changes in EEG displayed maladaptive } \\
\text { behaviour. This difference was not statistically significant }\end{array}$ \\
\hline $\begin{array}{l}\text { Collacott et al } \\
\qquad(1998),{ }^{58} \text { UK }\end{array}$ & $\begin{array}{l}\text { Cross-sectional } \\
\text { study }\end{array}$ & 372 with SIB; 1729 without SIB & Mean: 33.56 & DAS & $\chi^{2}$ & $\begin{array}{l}\text { No significant difference in seizure frequency between SIB and the } \\
\text { non-SIB group ( } \chi^{2}=2.36, \text { d.f. }=1, P=0.13 \text { ) }\end{array}$ \\
\hline $\begin{array}{l}\text { Deb \& Joyce } \\
\quad(1999){ }_{1}^{55} \text { UK }\end{array}$ & $\begin{array}{l}\text { Retrospective } \\
\text { study }\end{array}$ & 143 with epilepsy & $20-83$ & $\begin{array}{l}\text { Case notes; purpose- } \\
\text { designed } \\
\text { proforma }\end{array}$ & $\chi^{2}$ & $\begin{array}{l}\text { Statistically significant higher rate of challenging behaviour among } \\
\text { those with GTCS (63\%) than those without GTCS }(31 \%)\left(\chi^{2}=5.9 \text {, d.f. }\right. \\
=1, P=0.01) \text {. No intergroup difference in any other seizure type, } \\
\text { seizure frequency or type of AED use }\end{array}$ \\
\hline
\end{tabular}




\begin{tabular}{|c|c|c|c|c|c|c|}
\hline $\begin{array}{l}\text { Deb \& Joyce } \\
\quad(1999){ }_{1}^{56} \text { UK }\end{array}$ & $\begin{array}{l}\text { Retrospective } \\
\text { study }\end{array}$ & 143 with epilepsy & $20-83$ & $\begin{array}{l}\text { Case notes; purpose- } \\
\text { designed } \\
\text { proforma }\end{array}$ & $\chi^{2}$ & $\begin{array}{l}46 \% \text { with challenging behaviour compared with } 42 \% \text { without such } \\
\text { behaviour received AED polypharmacy. This difference was not } \\
\text { statistically significant } \\
\text { Among AED monopharmacy, } 59 \% \text { of those receiving carbamazepine } \\
55 \% \text { sodium valproate, } 53 \% \text { phenytoin and } 78 \% \text { receiving } \\
\text { lamotrigine showed challenging behaviour. None of these } \\
\text { differences were significant }\end{array}$ \\
\hline $\begin{array}{l}\text { Andrews et al } \\
\qquad(1999){ }_{1}^{67} \text { UK }\end{array}$ & $\begin{array}{l}\text { Observational } \\
\text { study }\end{array}$ & 116 with epilepsy & $18-93$ & $\begin{array}{l}\text { ABC subdomain } \\
\text { scores }\end{array}$ & $\chi^{2}$ & $\begin{array}{l}\text { Participants with generalised seizures (median: } 8.5 \text { ) had non- } \\
\text { significantly higher ABC subscores than those with partial seizures } \\
\text { (median: 1), apart from hyperactivity and inappropriate speech, } \\
\text { which were significantly higher (hyperactivity subscore; } \chi^{2}=11.4 \text {, } \\
\text { d.f. }=2, P=0.003 ; \text { inappropriate speech subscore; } \chi^{2}=6, \text { d.f. }=2 ; P \\
=0.048 \text { ). No significant associations were found between the } \\
\text { category of MRI abnormalities (focal v. diffuse cerebral } v \text {. no lesion) } \\
\text { and the ABC factors } \\
\text { No significant association between ABC scores and number and type } \\
\text { of AED prescribed }\end{array}$ \\
\hline $\begin{array}{l}\text { Espie et al } \\
\qquad(2003){ }^{46} \text { UK }\end{array}$ & $\begin{array}{l}\text { Cross-sectional } \\
\text { study }\end{array}$ & $\begin{array}{l}178 \text { with epilepsy compared with } 1022 \\
\text { normative non-epilepsy } \\
\text { standardisation group }\end{array}$ & Mean: 35.5 & ABC subdomains & $\begin{array}{l}\text { Compared scores with } \\
\text { normative data } \\
\text { using Cronbach's } \\
\text { alpha }\end{array}$ & $\begin{array}{l}\text { ABC scores were most strongly related to non-epilepsy-specific } \\
\text { concerns such as intellectual, sensory or motor function rather } \\
\text { than epilepsy-specific concerns such as seizure severity and } \\
\text { frequency }\end{array}$ \\
\hline $\begin{array}{l}\text { Turkistani } \\
\qquad(2004),{ }^{47} \text { UK }\end{array}$ & $\begin{array}{l}\text { Unmatched } \\
\text { controlled } \\
\text { study }\end{array}$ & 108 with epilepsy; 132 without epilepsy & Mean: 40.3 & $\begin{array}{l}\text { Parents' and carers' } \\
\text { report of disturbed } \\
\text { behaviour }\end{array}$ & $\chi^{2}$ & $\begin{array}{l}\text { Seizure frequency did not have a significant effect on the rate of } \\
\text { challenging behaviour. No significant difference in the rate of } \\
\text { challenging behaviour between those who received AED } \\
\text { monopharmacy } v \text {. those who received AED polypharmacy }\end{array}$ \\
\hline $\begin{array}{l}\text { Ring et al } \\
\qquad(2007){ }^{57} \text { UK }\end{array}$ & $\begin{array}{l}\text { Observational } \\
\text { study }\end{array}$ & $\begin{array}{l}110 \text { with active epilepsy (at least one } \\
\text { seizure in the past } 3 \text { months); } 65 \text { with } \\
\text { non-active epilepsy (no seizures in the } \\
\text { past } 3 \text { months) }\end{array}$ & $16-72$ & $\begin{array}{l}\text { Case notes and carer } \\
\text { interviews }\end{array}$ & $\chi^{2}$ & $\begin{array}{l}\text { No statistically significant difference in the rate of challenging } \\
\text { behaviour between active epilepsy (19\%) and non-active epilepsy } \\
\text { group (18\%). SIB was displayed by } 7 \% \text { of the non-active and } 9 \% \text { o } \\
\text { the active epilepsy groups. This difference was not statistically } \\
\text { significant }\end{array}$ \\
\hline $\begin{array}{l}\text { van Ool et al } \\
(2018)^{72} \\
\text { Netherlands }\end{array}$ & $\begin{array}{l}\text { Cross-sectional } \\
\text { design }\end{array}$ & 189 with epilepsy & $18-85$ & BPI (Dutch version) & Regression analysis & $\begin{array}{l}\text { SIB significantly associated with a lower number of AED (OR }=0.54, P= \\
\text { 0.018). Stereotyped behaviour significantly associated with a higher } \\
\text { number of seizure types (OR=1.56, } P=0.001 \text { ), a higher seizure } \\
\text { frequency (OR=1.02, } P=0.015) \text {, a lower number of AEDS (OR }= \\
0.70, P=0.048) \text {. Aggressive/destructive behaviour was significantly } \\
\text { associated with a higher number of seizure types ( } O R=1.42, P= \\
\text { 0.006) }\end{array}$ \\
\hline $\begin{array}{l}\text { Blickwedel et al } \\
\text { (2019), }{ }^{53} \text { UK }\end{array}$ & $\begin{array}{l}\text { Unmatched } \\
\text { controlled } \\
\text { study }\end{array}$ & $\begin{array}{l}238 \text { with challenging behaviour, including } \\
70 \text { with epilepsy }\end{array}$ & $\begin{array}{l}\text { Epilepsy group, } \\
\text { mean: } 40.2 ; \text { non- } \\
\text { epilepsy group, } \\
\text { mean: } 38\end{array}$ & $A B C-C$ & $\begin{array}{l}\text { Multiple regression } \\
\text { analysis }\end{array}$ & $\begin{array}{l}\text { No significant difference in ABC-C scores between those with focal } \\
\text { and primary generalised seizures or between those receiving AED } \\
\text { mono- or polypharmacy }\end{array}$ \\
\hline
\end{tabular}


Std. Mean difference

Study or Subgroup

Std. Mean difference

Blickwedel et al, $2019^{53}$

$-0.1803$

0.2973

Deb et al, $1987^{36}$

Deb et al, $2001^{12}$

Deb, 199740

Espie et al, $1989^{37}$

Espie et al, $2003^{46}$

Fitzgerald et al, $2011^{50}$

Gillies et al, 198938

Matson et al, 199941

Matthews et al, $2008^{43}$

McGrother et al, $2006^{48}$

O'Dwyer et al, $2018^{51}$

Pawar \& Akuffo, $2008^{49}$

Prasher, $1995^{45}$

Smith \& Matson, 2010a44

Turkistani, $2004^{47}$

0.51899382

0.13380051

0.359

$-0.4205$

0.3451

0.5014

$-0.4678$

0.1177578

0.27019213

0.10458161

$-0.2822656$

0.2371

0.1237

$-0.25403904$

$\begin{array}{rr}\text { s.e. } & \text { Weigh } \\ 0.1425 & 6.8 \% \\ 0.2515 & 5.1 \%\end{array}$

$0.2515 \quad 5.1 \%$

$0.2877786 \quad 4.6 \%$

$0.12817725 \quad 7.0 \%$

$0.3685 \quad 3.6 \%$

$0.0817 \quad 7.6 \%$

$0.1172 \quad 7.2 \%$

$0.1782 \quad 6.3 \%$

$0.0763 \quad 7.7 \%$

$0.2552519 \quad 5.1 \%$

$0.05176707 \quad 7.9 \%$

$0.09140554 \quad 7.5 \%$

$0.18793817 \quad 6.1 \%$

$0.1932 \quad 6.0 \%$

$0.2831 \quad 4.7 \%$

$6.7 \%$

Total $(95 \% \mathrm{Cl})$

$100.0 \%$

Heterogeneity: $\operatorname{Tau}^{2}=0.11 ; \mathrm{Chi}^{2}=124.20, \mathrm{df}=15(P<0.00001) ; I^{2}=88 \%$

Test for overall effect: $Z=0.62(P=0.53)$
IV Random, 95\% Cl

$-0.18(-0.46$ to 0.10$)$

$0.30(-0.20$ to 0.79$)$

$0.52(-0.05$ to 1.08$)$

$0.13(-0.12$ to 0.39$)$

$0.36(-0.36$ to 1.08$)$

$-0.42(-0.58$ to -0.26$)$

0.35 ( 0.12 to 0.57$)$

$0.50(0.15$ to 0.85$)$

$-0.47(-0.62$ to -0.32$)$

$0.12(-0.38$ to 0.62$)$

0.27 (0.17 to 0.37 )

$0.10(-0.07$ to 0.28$)$

-0.28 (-0.65 to 0.09$)$

$0.24(-0.14$ to 0.62$)$

$0.12(-0.43$ to 0.68$)$

-0.25 ( -0.56 to 0.05$)$

$0.06(-0.13$ to 0.24$)$

V, Random 95\% C

IV, Random, $95 \%$

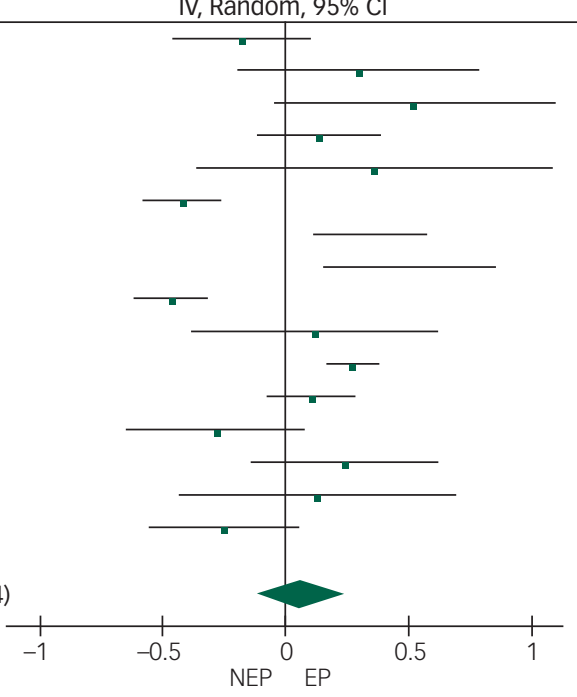

Fig. 2 Forest plot of total challenging behaviour score data from 16 studies.

NEP, no epilepsy; EP, epilepsy.

group, with a very small effect size of 0.16 . The heterogeneity level was low $\left(I^{2}=27 \%\right)$. The self-injurious behaviour meta-analysis also showed a statistically significant higher rate in the epilepsy group compared with the non-epilepsy group, with a very small effect size of 0.28 , but the heterogeneity score was high, albeit below $60 \%\left(I^{2}=54 \%\right)$. The stereotypy meta-analysis did not show any significant intergroup difference but showed a high heterogeneity value of over $60 \%\left(I^{2}=69 \%\right)$.

\section{Quality control}

The AMSTAR2 checklist showed a high score, indicating that this systematic review and meta-analysis is of a high standard (supplementary Appendix 3). The SIGN 50 checklist identified only 5 of the 32 studies to be of high quality and the Cochrane risk-of-bias assessment of the 19 controlled studies showed a high risk of bias in most domains for most of the studies (Fig. 7). A summary graph is presented as supplementary Appendix 5. Publication bias could not be identified using a funnel plot for stereotypy, as data from only three studies could be amalgamated into the meta-analysis. Funnel plot data showed no publication bias for aggression, which was further supported by Egger's test of publication bias $(P=0.213) .^{80}$ Although the funnel plot showed some publication bias for overall rate of challenging behaviour, this was not significant under Egger's test of publication bias $(P=0.734)$. There was no publication bias present for self-injurious behaviour $(P=$ 0.307). Eleven articles reported receiving funding from external sources, one did not receive any funding and the rest $(n=22) \mathrm{did}$ not declare the funding source.

Std. Mean difference

Std. Mean difference

Study or Subgroup Std. Mean difference s.e. Weight

IV random, IV, Random, 95\% Cl

Blickwedel et al $2019^{53}$ $-0.1803$ $0.1425 \quad 6.8 \%$

-0.18 (-0.46 to 0.10)

$0.30(-0.20$ to 0.79$)$

$0.52(-0.05$ to 1.08$)$

$0.13(-0.12$ to 0.39$)$

$0.36(-0.36$ to 1.08$)$

$0.51899382-0.2877786 \quad 4.6 \%$

Deb et al, $2001^{12}$

Deb, 199740

Espie et al, $1989^{37}$

Espie et al, $2003^{46}$

Fitzgerald et al, $2011^{50}$

Gillies et al, 198938

Matson et al, 199941

Matthews et al, $2008^{43}$

McGrother et al, $2006^{48}$

O'Dwyer et al, $2018^{51}$

Pawar \& Akuffo, $2008^{49}$

Prasher, $1995^{45}$

Smith \& Matson, 2010a44

Turkistani, $2004^{47}$

$\begin{array}{lll}0.13380051 & 0.12817725 & 7.0 \%\end{array}$

$0.359-0.3685-3.6 \%$

$\begin{array}{lll}-0.4205 & 0.0817 \quad 7.6 \%\end{array}$

$\begin{array}{lll}0.3451-0.1172 & 7.2 \%\end{array}$

$\begin{array}{lll}0.5014 & 0.1782 \quad 6.3 \%\end{array}$

$\begin{array}{lll}-0.4678 & 0.0763 & 7.7 \%\end{array}$

$\begin{array}{lll}0.1177578 & 0.2552519 & 5.1 \%\end{array}$

$\begin{array}{lll}0.27019213 & 0.05176707 & 7.9 \%\end{array}$

$\begin{array}{lll}0.10458161 & 0.09140554 & 7.5 \%\end{array}$

$\begin{array}{lll}-0.2822656 & 0.18793817 & 6.1 \%\end{array}$

$\begin{array}{lll}0.2371 & 0.1932 & 6.0 \%\end{array}$

$\begin{array}{lll}0.1237 & 0.2831 \quad 4.7 \%\end{array}$

$\begin{array}{lll}-0.25403904 & 0.15430887 & 6.7 \%\end{array}$

Total $(95 \% \mathrm{Cl})$

$100.0 \%$

Heterogeneity: $\mathrm{Tau}^{2}=0.01 ; \mathrm{Chi}^{2}=10.94, \mathrm{df}=9(P<0.28) ; I^{2}=18 \%$

Test for overall effect: $Z=2.62(P=0.007)$

$-0.42(-0.58$ to -0.26$)$

0.35 (0.12 to 0.57$)$

0.50 (0.15 to 0.85$)$

$-0.47(-0.62$ to -0.32$)$

$0.12(-0.38$ to 0.62$)$

0.27 (0.17 to 0.37$)$

$0.10(-0.07$ to 0.28$)$

-0.28 (-0.65 to 0.09$)$

0.24 (-0.14 to 0.62$)$

$0.12(-0.43$ to 0.68$)$

-0.25 (-0.56 to 0.05$)$

$0.06(-0.13$ to 0.24$)$

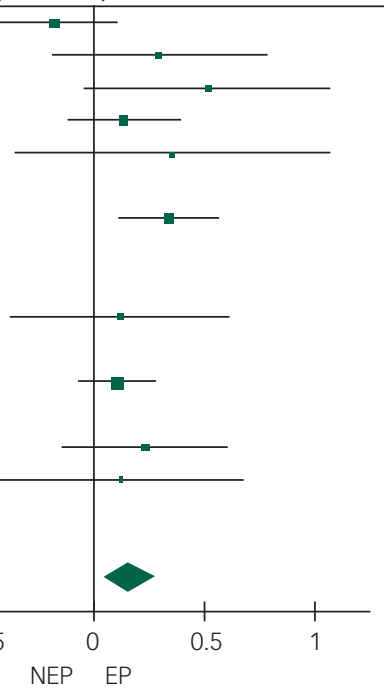

Fig. 3 Forest plot of total challenging behaviour score data from 10 studies after sensitivity analysis 


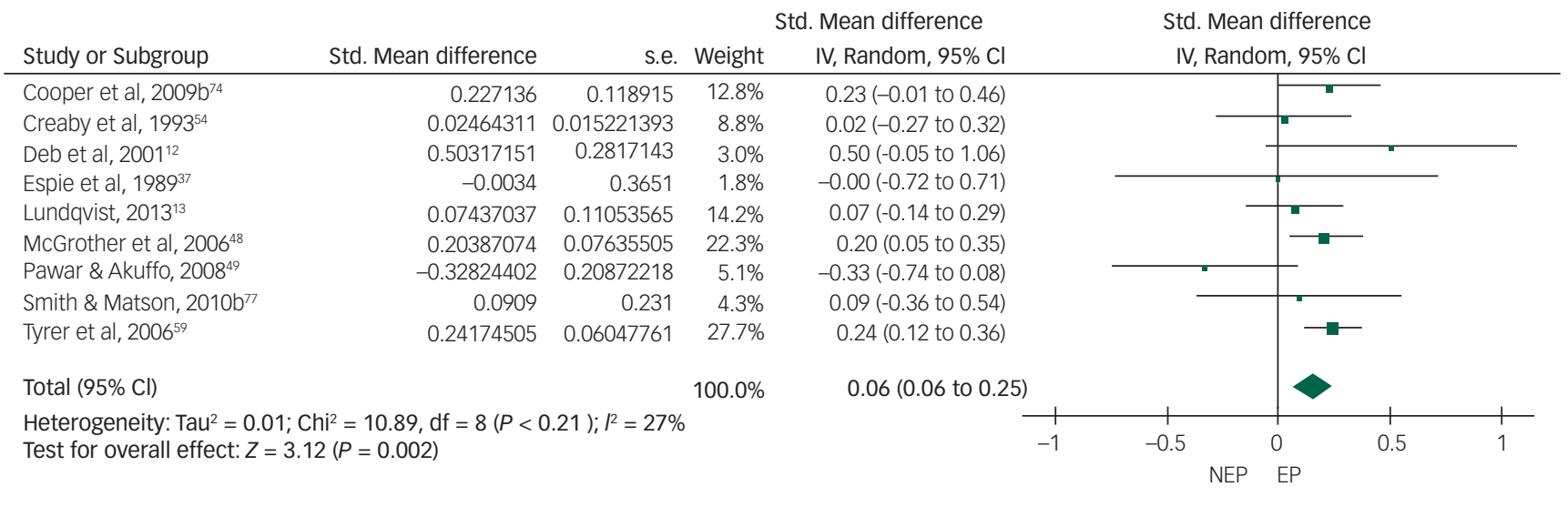

Fig. 4 Forest plot of aggression score data.

\section{Discussion}

We included 34 articles in our systematic review that met the eligibility criteria. These included 9 studies that compared the overall rate of challenging behaviour in an epilepsy group with a matched control group and another 10 that compared data with an unmatched control group. Compared with previous systematic reviews this review included data for a much higher number of participants (Table 4).

In our review, of the total 19 controlled studies, $13^{12,36,37,39,40,43-45,47,50-53}$ did not show any significant intergroup difference in the overall rate of challenging behaviour, $3^{38,42,48}$ showed a significantly higher rate of challenging behaviour in the epilepsy group and $3^{41,46,49}$ showed a higher rate in the non-epilepsy group. Of these three, one ${ }^{41}$ was at a significant level and the level of significance for the other two ${ }^{46,49}$ is not known.

It was possible to pool data from only 16 of the controlled studies for a meta-analysis. Meta-analysis of pooled data from these 16 studies did not show a significant intergroup difference in the overall rate of challenging behaviour but showed a high heterogeneity. However, after sensitivity analysis meta-analysis of pooled data from 10 studies showed a significantly higher rate of overall challenging behaviour in the epilepsy group compared with the non-epilepsy group. Meta-analysis of pooled data showed a statistically significant higher rate of aggression and self-injurious behaviour in the epilepsy group compared with the non-epilepsy group. However, no such intergroup difference emerged from the meta-analysis of pooled stereotype data.
A funnel plot and Egger's test of publication bias showed no publication bias among the included studies. According to both SIGN 50 and Cochrane risk-of-bias assessments most studies appeared to be of moderate to poor quality.

\section{Interpretation of meta-analyses findings}

Our finding (based on meta-analysis of pooled data from 10 studies) of a significant intergroup difference differs from that of other systematic reviews, ${ }^{19-21}$ which found no such difference. Our finding has to be interpreted with caution. First, when data from all available studies were pooled, no statistically significant intergroup difference emerged, although the heterogeneity among studies was very high. Second, even when the meta-analysis after the sensitivity analysis showed that the epilepsy group had a significantly higher rate of challenging behaviour, the effect size remained very small, so this may not be clinically significant. Third, different studies defined challenging behaviour in different ways. Some did not use any validated tool. Fourth, even when a validated scale was used, the total score was used to define challenging behaviour, which is not always valid. For example, a number of studies used the ABC-C total score, which is not valid. ${ }^{66}$ Fifth, many studies used an arbitrary cut-off score on behaviour rating scales to define challenging behaviour, and different studies used different scales and different cut-off scores. Thus, it is difficult to compare data among studies as it is difficult to know when data were pooled and whether all studies are describing the same challenging behaviour.

Deb \& Hunter ${ }^{61}$ hypothesised that it is possible that underlying brain damage (in adults with severe and profound

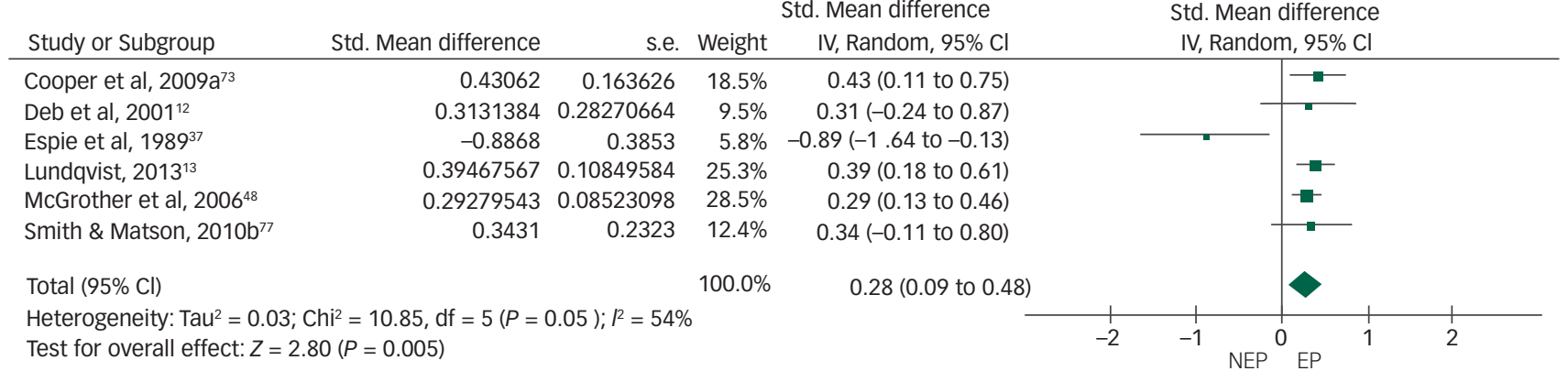




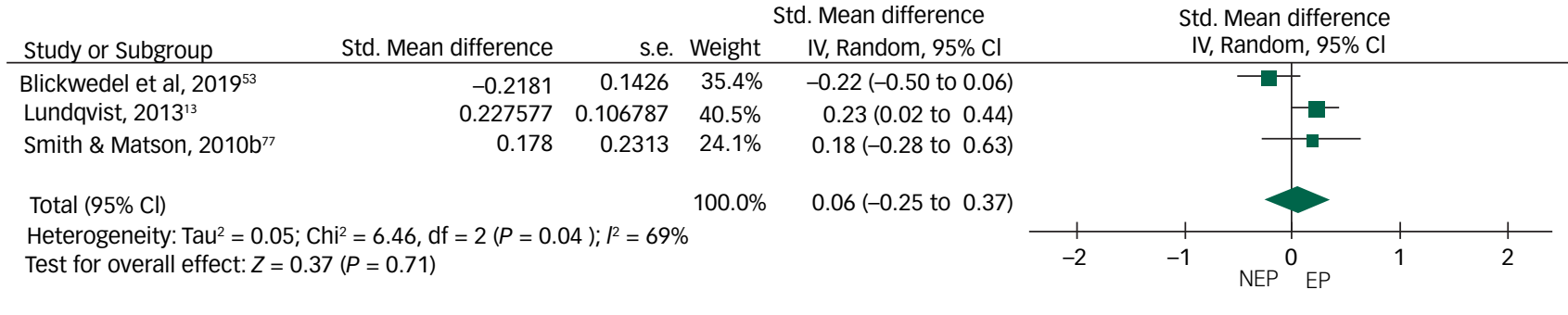

Fig. 6 Forest plot of stereotypy score data.

NEP, no epilepsy; EP, epilepsy.

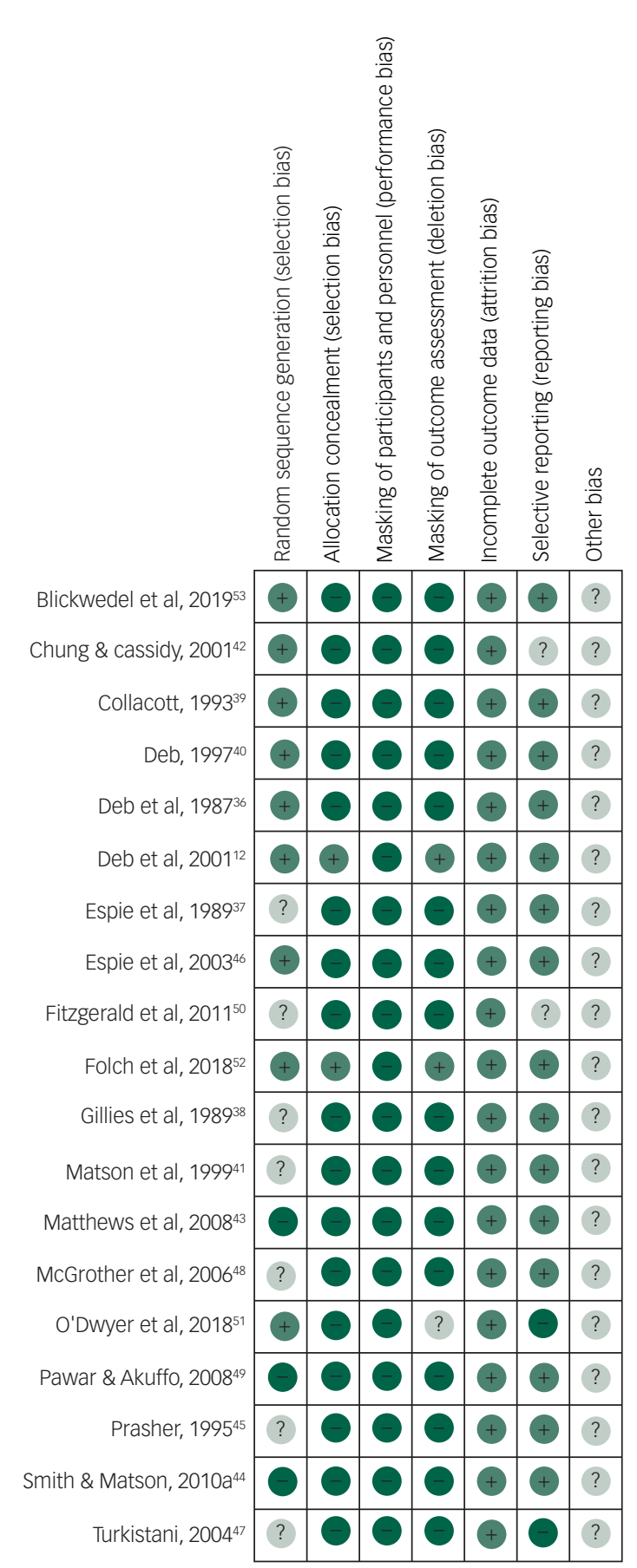

Fig. 7 Cochrane risk-of-bias summary for the 19 controlled studies.

+, bias present; -, bias absent; ?, bias possible. intellectual disabilities) and psychosocial factors (in those with mild intellectual disabilities) are stronger determinants of challenging behaviour than the presence of epilepsy. Factors that affect behaviour in the presence of epilepsy are related to: (a) underlying brain damage, such as the location and severity of any deformity, tumour or abnormal electrical discharge in the brain; (b) epilepsy-related factors, such as the presence of certain epileptic syndromes and genetic syndromes that are prone to lead to more challenging behaviour; (c) seizure-related factors, such as the severity, type and frequency of seizures; (d) anti-epileptic medication-related factors, such as the adverse effects of certain anti-epileptics and drug-drug interactions; and (e) psychosocial factors, such as loss of occupation, financial problems, lack of support, and locus of control being outside the person so the person does not have any control over the timing of seizures.

\section{Types of challenging behaviour}

Many types of challenging behaviour were assessed in the included studies. The most common types that cause most concern and are most difficult to manage are aggression (verbal or physical aggression towards other people or property) and self-injurious behaviour. Pooled data showed a statistically significant higher rate of both aggression and self-injurious behaviour in the epilepsy group compared with the non-epilepsy group. It is worth remembering that, apart from epilepsy, many other medical and psychosocial factors influence these behaviours, including certain genetic syndromes that are known to be associated with aggression and self-injurious behaviour. ${ }^{81}$ Many of these syndromes also tend to predispose individuals to epilepsy (examples include LeschNyhan and fragile-X syndromes). ${ }^{1}$ Therefore, it is difficult to draw any conclusion about the association between these specific challenging behaviours and epilepsy in isolation without considering all the other predisposing (e.g. genetic syndromes), precipitating (e.g. infection or anxiety) and perpetuating (e.g. inappropriate treatment and/or environment) factors for challenging behaviour in general. Pooled data did not show any significant intergroup difference in the rate of stereotyped behaviour. Only a small number of studies were involved in this meta-analysis and the heterogeneity level was high. Therefore, this finding has to be interpreted with caution.

The rates of other behaviours, such as inappropriate sexual behaviour, irritability, hyperactivity, verbal aggression, antisocial behaviours and lethargy, were reported in a very small number of studies showing equivocal findings. Therefore, it is difficult to draw any definitive conclusion about the association between these specific types of challenging behaviour and epilepsy. Another problem is that none of these specific behavioural types was defined using any standardised criteria (such as the Modified Overt Aggression Scale for rating aggression) $)^{15,82}$ but were based on single-item scoring. 
Systematic $\begin{array}{ll}\begin{array}{l}\text { de Winter et al } \\ (2011)^{20}\end{array} & \text { Only } 8 \text { out of } 45 \text { studies included participants with epilepsy. } \\ & \text { Total participants: not reported (5263 children and adults }\end{array}$ (n) study characteristics Table)

461 children and adolescents, 7742 adults and elderly, and 392 participants of mixed age groups. Total number of participants with epilepsy was not reported

Blickwedel et a $(2019)^{19}$

Deb et al (2020) (current review)

\section{Study characteristics}

Search strategy: English, Dutch or German language studies published between January 1990 and July 2008 with a minimum sample size of five participants.

Included studies: 45 papers involving children and adults with intellectua disabilities, only 8 of which included participants with epilepsy. All physical and medical conditions were included. All levels of intellectua disability were included.

outcome: Main aim was to find prevalence of different medical conditions, including epilepsy. Within that context, challenging behaviour was compared between those with and without epilepsy in 8 studies only.

Data analysis: Only narrative synthesis, no meta-analysis

Search strategy: English language studies published between January 1995 and January 2015.

Included studies: 15 papers involving children and adults with intellectua disabilities (9: presence and absence of epilepsy in people with intellectual disabilities; 4: differences in epilepsy-related factors in people with intellectual disabilities and epilepsy; 4: presence or absence of intellectual disabilities in people with epilepsy). All types of epilepsy and all levels of intellectual disability were included.

Outcome: Neuropsychiatric comorbidity in general, no separate data on challenging behaviour.

Data analysis: Only narrative synthesis, no meta-analysis

Search strategy: English language studies published between January 1985 and August 2016 with a minimum sample size of five participants. Included studies: 25 articles involving adults only with any level of intellectual disability.

Outcome: Overall challenging behaviour, different types of challenging behaviour, challenging behaviour according to different epilepsy variables.

Data analysis: Only narrative synthesis, no meta-analysis

Search strategy: English language articles published between January 1985 and May 2020.

Included studies: 34 articles based on 32 studies involving adults with intellectual disabilities only. 19 controlled studies ( 9 with and 10 without a matched control group).

Outcome: Overall challenging behaviour, different types of challenging behaviour and challenging behaviour according to different epilepsy variables (seizure frequency, generalised $v$. focal seizures, generalised $v$. focal EEG changes, polypharmacy $v$. monopharmacy with antiepileptics).

Data analysis: Narrative synthesis and meta-analysis
No significant association was found between epilepsy and challenging behaviour.

People with more severe and frequent seizures may be at a higher risk of developing challenging behaviour

Presence of epilepsy only is not a clear determinant of neuropsychiatric comorbidity in people with intellectual disabilities.

More severe forms of epilepsy had an association, but most included studies showed a high risk of bias

No significant association between epilepsy and overall challenging behaviour

No significant association between overall challenging behaviour and aggression, self-injurious behaviour and stereotypy.

Significantly higher rate of irritability was associated with epilepsy.

More frequent seizures were associated with self-injurious behaviour and antisocial behaviour. Limited evidence that generalised epilepsy may be associated with challenging behaviour

The narrative analysis of data from 34 included articles showed no significant association between epilepsy and challenging behaviour. No definite association was found in the rate of challenging behaviour and different epilepsy variables, such as frequency of seizures, generalised $v$. focal epilepsy, polypharmacy of anti-epileptic drugs (narrative analysis only).

Meta-analysis was possible on pooled data from only 16 controlled studies. This showed no significant intergroup difference but, after sensitivity analysis, pooled data from 10 studies showed a significantly higher rate of overall challenging behaviour in the epilepsy group (effect size: 0.16 ) compared with the non-epilepsy group.

Aggression and self-injurious behaviour both showed a statistically significant higher rate in the epilepsy group, with a very small effect size ( 0.16 and 0.28 respectively). No significant intergroup difference was observed in the rate of stereotypy 


\section{Association with epilepsy variables}

When different subgroups according to various epilepsy variables were compared for the rate of challenging behaviour no clear picture emerged. In three studies ${ }^{54,61,72}$ the rate of challenging behaviour was significantly higher in those who had generalised seizures compared with those who had focal seizures, but in one study ${ }^{67}$ no significant difference was reported between these two groups. Given the small number of studies involving small numbers of participants in the subgroups, lack of matching of the groups, and different types of challenging behaviour rated in these studies, it is difficult to draw any definitive conclusion about any association between challenging behaviour and seizure type. Furthermore, Deb $^{62}$ has shown that a high proportion of adults with intellectual disabilities who had a clinical diagnosis of primary generalised seizure showed focal epileptiform changes in their EEGs, thus raising the possibility that in many cases these generalised seizures are secondarily generalised from focal seizures.

Although three studies ${ }^{38,61,72}$ showed a significantly higher rate of challenging behaviour among those who had frequent seizures compared with those who had less frequent seizures, five studies ${ }^{37,47,54,55,58}$ did not find any significant intergroup difference. Therefore, it is difficult to draw any definitive conclusion about the influence of seizure frequency on the rate of challenging behaviour in this population. One confounder is the way frequency was rated in different studies, which varied widely. One study ${ }^{61}$ showed a significantly higher rate of challenging behaviour in those whose EEGs showed generalised epileptiform activities compared with those whose EEGs showed focal epileptiform changes. However, in another three studies ${ }^{53,62,67}$ no significant intergroup difference emerged between those with generalised as opposed to focal EEG changes. It is difficult to carry out an EEG for many adults with intellectual disabilities, particularly those who have severe and profound disability and also those who have challenging behaviour. EEG records are available for approximately $50-70 \%$ of adults with intellectual disabilities and $70-90 \%$ of these recordings are abnormal, although the abnormalities are not necessarily epileptiform in nature; rather, they present mostly as non-specific excess slow background activity. ${ }^{62}$

\section{Association with anti-epileptic medication}

No definite association was found in the rate of challenging behaviour and polypharmacy with anti-epileptic medications. One would expect the participants in the polypharmacy group to have more severe epilepsy and, therefore, possibly more challenging behaviour. However, it is possible that anti-epileptic polypharmacy made these participants more sedated, thus dampening down the expression of challenging behaviour. In some people anti-epileptics improve both epilepsy symptoms and behaviour. However, in others it can have an opposite effect, in that although the epilepsy improves, the behaviour deteriorates. ${ }^{9}$ There may be many explanations for this paradoxical response. Old theories, such as forced normalisation ${ }^{83}$ or alternative psychosis, ${ }^{84}$ may provide some explanation. However, a more practical explanation may be that medication side-effects make the behaviour worse in some, despite improving epilepsy symptoms.

Although certain anti-epileptics, such as sodium valproate (restricted use in women of child-bearing age because of major worry about its teratogenicity), carbamazepine and lamotrigine, are known to improve mental state and are used to treat psychiatric disorders such as bipolar disorder, ${ }^{85}$ paradoxically some anti-epileptics are known to precipitate psychopathology, including challenging behaviour. ${ }^{86}$

Although the evidence is not strong, the available data suggest that the following anti-epileptic medications are likely to have some association with aggression and other challenging behaviours: phenobarbital, topiramate, vigabatrin, perampanel, zonisamide, levetiracetam, clobazam, clonazepam and tiagabine. Among these perhaps levetiracetam (aggression or agitation in 13\% of treated patients), perampanel (in $12 \%$ at $8 \mathrm{mg}$ /day and $20 \%$ at $12 \mathrm{mg} /$ day) and possibly topiramate (in 2-10\%) showed the strongest evidence for precipitating challenging behaviour. ${ }^{86}$ However, levetiracetam seems to improve behaviour in some adults with intellectual disabilities and worsen it in others. ${ }^{87}$ These anti-epileptic-related adverse effects may be more pronounced among adults with intellectual disabilities. ${ }^{5}$ However, it is clear that vast majority of those who receive these medications do not show any challenging behaviour. It is difficult to draw any definite conclusion from this review, as only one study reported the rate of challenging behaviour related to specific anti-epileptic drugs (59\% of participants on carbamazepine, $55 \%$ on sodium valproate, $53 \%$ on phenytoin and $78 \%$ on lamotrigine monopharmacy showed challenging behaviour).

Although monopharmacy with anti-epileptic medication is desirable, ${ }^{88}$ polypharmacy with anti-epileptics is common in intellectual disability populations. Therefore, anti-epileptic drug-drug interaction are more likely, some of which may lead to challenging behaviour. Given that both antipsychotic and antidepressant medications are commonly prescribed among adults with intellectual disabilities, ${ }^{89}$ their interaction with anti-epileptics must be considered in any assessment of challenging behaviour. Also, both antipsychotics and antidepressants are likely to lower seizure threshold (particularly the older generation ones and at a high dose), which may precipitate more seizures and may lead to challenging behaviour.

Subgroup comparisons do not provide adequate power to detect clinically significant difference because of the small numbers involved in each subgroup and the lack of a control group. Also, in the subgroups there is no consistency in the types of challenging behaviour described, as some studies provided the rate of overall challenging behaviour, but others reported the rates of different types of challenging behaviour, such as aggression, self-injurious behaviour and stereotypy, making it difficult to amalgamate data from different studies. It will be necessary to conduct a much larger randomised controlled trial to recruit a reasonable number of participants in each subgroup to provide adequate power to detect clinically significant intergroup differences.

\section{Clinical significance of the findings}

Having epilepsy can restrict social activities and wider social integration. A careful risk assessment is necessary to balance independence/quality of life and seizure-related risks (e.g. travelling alone, taking a bath, seizure-related injuries, unpredictability of the timing of seizures, SUDEP). The risk assessment should be part of the person's overall person-centred support plan and should be monitored and reviewed regularly with the person, their family/ caregivers, other relevant professionals and the multidisciplinary team. One has to remember to mitigate against the impact on the family/caregivers. It is also important to remember that, apart from epilepsy, many circumstances, such as medical, psychological, social and environmental factors, affect the behaviour of someone with intellectual disabilities, and a full multidisciplinary personcentred assessment is required to develop an appropriate formulation for the management of challenging behaviour, including psychosocial interventions. ${ }^{10}$ Support staff, and the person and their family/carers, need to be informed of the risk factors (including SUDEP) and prognosis. ${ }^{90-92}$ This also highlights the requirement for regular health checks for all adults with intellectual disabilities, as highlighted in a recent NHS England publication..$^{93}$ 


\section{Strengths}

Our review received a high rating on the AMSTAR 2 quality control checklist for systematic reviews, as we complied with all of its requirements (supplementary Appendix 3). We carried out metaanalyses that were not done in any previous systematic reviews. We included a comprehensive Cochrane risk-of-bias table, which was not done by any of the previous systematic reviews. We included a much higher number of articles covering data from a much larger number of participants compared with the previous systematic reviews. We have registered our review with a well-established database, PROSPERO, so that our protocol is available for public scrutiny. This was not done by the previous reviews. We also carried out a very extensive hand-search of journals in the field of intellectual disability and epilepsy, along with stringent cross-referencing.

\section{Weaknesses}

We searched for articles in English only. We excluded the grey literature and conference abstracts, as we felt it would be difficult to apply our eligibility criteria and risk-of-bias assessment on the basis of abstracts only. Although we used a stringent method for literature search, it is still possible that we missed some relevant articles. Our analysis showed conflicting evidence, in that the metaanalysis of pooled data from a larger number of studies did not show a significant intergroup difference, whereas pooled data from a smaller number of studies after sensitivity analysis showed a significant difference. Although we amalgamated data where possible to carry out a number of meta-analyses, the heterogeneity among studies remains high. It is difficult to amalgamate data from studies that used such diverse methodologies and defined challenging behaviour in so many different ways. Therefore, our findings must be interpreted with caution, as a lot of confounders could not be controlled for. However, to counteract the problem with study heterogeneity we used sensitivity analyses. Ideally, we should have used raw data for the meta-analysis, but this was not possible. Also, by log-transforming some data we may have lost some power in the meta-analysis.

\section{Research implications}

Even though the meta-analysis of pooled data from a smaller number of studies after sensitivity analysis showed a significantly higher rate of challenging behaviour in the epilepsy group, the effect sizes are small, which may not be clinically significant. Also, there are major methodological flaws (highlighted by Cochrane risk-of-bias and SIGN 50 assessments) in the included studies. There is therefore a need for large-scale properly controlled studies. The included studies primarily concentrated on inter-ictal challenging behaviour. However, peri-ictally some people may show aggression, which is not goal directed but inadvertently may injure others. This might also be studied in further research.

Shoumitro Deb (D), MBBS, FRCPsych, MD, Faculty of Medicine, Department of Brain Sciences, Imperial College London, UK; Basma Akrout Brizard, BSC, MSc, Institut de Psychologie, Laboratoire de Psychopathologie et Processus de Santé, Paris, France; Bharati Limbu, BSc, Faculty of Medicine, Department of Brain Sciences, Imperial College London, UK

Correspondence: Shoumitro Deb. Email: s.deb@imperial.ac.uk

First received 19 Jun 2020, final revision 28 Jul 2020, accepted 18 Aug 2020

\section{Supplementary material}

Supplementary material is available online at http://doi.org/10.1192/bjo.2020.96

\section{Data availability}

Data availability is not applicable to this article as no new data were created or analysed in this study.

\section{Author contribution}

B.A.B. and S.D. conceptualised and designed the study. B.A.B. carried out the literature search. B.A.B. and B.L. screened bibliographies and extracted data and completed risk-of-bias checklist. B.L. carried out meta-analysis. All authors contributed to manuscript writing and authorised the final version of the manuscript.

\section{Funding}

B.L. is funded by the UK'S National Institute of Health Research (NIHR) Research for Patient Benefit (RfPB) Programme (grant PBPG-0817-20010). The Imperial Biomedical Research Centre Facility, which is funded by the NIHR, has provided support for the study. The views expressed in this article are those of the authors and not necessarily those of the National Health Service, the NIHR, or the Department of Health, UK.

\section{Declaration of interest}

None.

ICMJE forms are in the supplementary material, available online at http://doi.org/10.1192/ bjo.2020.96.

\section{References}

1 Deb S. Epidemiology and treatment of epilepsy in patients who are mentally retarded. CNS Drugs 2000; 13: 117-28.

2 Deb S, Joyce J. Characteristics of epilepsy in a population based cohort of adults with learning disability. Ir J Psych Med 1999; 16: 5-9.

3 Clarke DJ, Deb S. Syndromes causing intellectual disability. In New Oxford Textbook of Psychiatry (2nd edn) (eds MG Gelder, N Andreasen, JJ López-Ibor Jr, JR Geddes): 1838-48. Oxford University Press, 2009.

4 Berney T, Deb S. Epilepsy in learning disability. In Oxford Textbook of Epilepsy and Epileptic Seizures (eds S Shorvon, R Guerrini, M Cook, S Lahtoo): 195-9. Oxford University Press, 2012.

5 Shankar R, Watkins LV, Alexander R, Devapriam J, Dolman J, Hari A, et al. Prescribing Anti-Epileptic Drugs for People with Epilepsy and Intellectual Disability (College Report CR206). Royal College of Psychiatrists, 2017

6 Deb S. Epilepsy in people with mental retardation. In Handbook of Mental Retardation and Developmental Disabilities (eds JW Jacobson, JA Maulick): 81-96. Kluwer Academic Publishers, 2007.

7 Shankar R, Eyeoyibo M, Scheepers M, Dolman J, Watkins LV, Attavar R, et al. Good Psychiatric Practice: Management of Epilepsy in Adults with Intellectual Disability (College Report CR203). Royal College of Psychiatrists, 2017.

8 Kerr MP, Mensah S, Besag F, De Toffol B, Ettinger A, Kanemoto K, et al. International consensus clinical practice statements for the treatment of neuropsychiatric conditions associated with epilepsy. Epilepsia 2011; 52: 2133-8.

9 Deb S. Mental health and epilepsy among adults with intellectual disabilities. In Psychiatric and Behavioural Disorders in Intellectual and Developmental Disabilities (2nd edn) (eds N Bouras, G Holt): 238-51. Cambridge University Press, 2007.

10 Deb $S$, Kwok $H$, Bertelli $M$, Salvador-Carulla $L$, Bradley $E$, Torr J, et al. International guide to prescribing psychotropic medication for the management of problem behaviours in adults with intellectual disabilities. World Psychiatry 2009; 8: 181-6.

11 Smith S, Branford D, Collacott RA, Cooper SA, McGrother C. Prevalence and cluster typology of maladaptive behaviours in a geographically defined population of adults with learning disabilities. Br J Psychiatry 1996; 169: 219-27.

12 Deb S, Thomas M, Bright C. Mental disorder in adults with intellectual disability. 2: The rate of behaviour disorders among a community-based population aged between 16 and 64 years. J Intellect Disabil Res 2001; 45: 506-14.

13 Lundqvist LO. Prevalence and risk markers of behavior problems among adults with intellectual disabilities: a total population study in Örebro County, Sweden. Res Dev Disabil 2013; 34: 1346-56.

14 Hemmings C, Deb S, Chaplin E, Hardy S, Mukherjee R. Research for people with intellectual disabilities and mental health problems: a view from the UK. J Ment Health Res Intellect Disabil 2013; 6: 127-58.

15 Deb S, Deb T. Neuropsychiatry of aggression. In Oxford Textbook of Neuropsychiatry (eds R Faruqui, M Bodani, N Agrawal): 379-91. Oxford University Press, 2020.

16 Deb S, Bethea T, Havercamp S, Rifkin A, Underwood L. Disruptive, impulse-control, and conduct disorders. In Diagnostic Manual -Intellectual Disability: A Textbook of Diagnosis of Mental Disorders in Persons with Intellectual Disability (2nd edn) (eds R Fletcher, J Barnhill, S-A Cooper): 521-60. NADD Press, 2016. 
17 Sjgafoos J, Elkins J, Kerr M, Attwood T. A survey of aggressive behaviour among a population of persons with intellectual disability in Queensland. J Intellect Disabil Res 1994; 38: 369-81

18 Deb S, Unwin GL, Rojahn J, Cooper SA. Problem behaviours. In Textbook of Psychiatry for Intellectual Disability and Autism Spectrum Disorder (eds MO Bertelli, S Deb, K Munir, A Hassiotis, L Salvador-Carulla). Springer International Publishing, 2021 (in press).

19 Blickwedel J, Ali A, Hassiotis A. Epilepsy and challenging behaviour in adults with intellectual disability: a systematic review. J Intellect Dev Disabil 2019; 44: 219-31

20 de Winter CF, Jansen AA, Evenhuis HM. Physical conditions and challenging behaviour in people with intellectual disability: a systematic review. J Intellect Disabil Res 2011; 55: 675-98.

21 van Ool JS, Snoeijen-Schouwenaars FM, Schelhaas HJ, Tan IY, Aldenkamp AP, Hendriksen JG. A systematic review of neuropsychiatric comorbidities in patients with both epilepsy and intellectual disability. Epilepsy Behav 2016; 60: 130-7.

22 PROSPERO. Guidance Notes for Registering a Systematic Review Protocol with PROSPERO. Centre for Reviews and Dissemination, University of York, 2016.

23 Moher D, Shamseer L, Clarke M, Ghersi D, Liberati A, Petticrew M, et al. Preferred reporting items for systematic review and meta-analysis protocols (PRISMA-P) 2015 statement. Syst Rev 2015; 4(1): 1.

24 Unwin GL, Deb $S$. The use of medication to manage problem behaviours in adults with a learning disability: a national guideline. Adv Ment Health Intellect Disabil 2010; 4(3): 4-11.

25 Lefebvre C, Glanville J, Briscoe S, Littlewood A, Marshall C, Metzendorf M-I, et al. Searching for and selecting studies. In Cochrane Handbook for Systematic Reviews of Interventions Version 6.0 (Updated July 2019) (eds JPT Higgins, J Thomas, J Chandler, M Cumpston, T Li, MJ Page, et al.). Cochrane, 2019 (www.training.cochrane.org/handbook).

26 Deb S, Farmah BK, Arshad E, Deb T, Roy M, Unwin GL. The effectiveness of aripiprazole in the management of problem behaviour in people with intellectua disabilities, developmental disabilities and/or autistic spectrum disorder: a systematic review. Res Dev Disabil 2014; 35: 711-25.

27 Tarrant N, Roy M, Deb S, Odedra S, Retzer A, Roy A. The effectiveness of methylphenidate in the management of attention deficit hyperactivity disorder (ADHD) in people with intellectual disabilities: a systematic review. Res Dev Disabil 2018; 83: 217-32.

28 Unwin GL, Deb S. Efficacy of atypical antipsychotic medication in the management of behaviour problems in children with intellectual disabilities and borderline intelligence: a systematic review. Res Dev Disabil 2011; 32: 2121-33.

29 Zotero. Zotero Version 5.0.83. Corporation for Digital Scholarship, 2006 (https:// www.zotero.org).

$30 \mathrm{Li} \mathrm{T,} \mathrm{Higgins} \mathrm{JPT,} \mathrm{Deeks} \mathrm{JJ.} \mathrm{Collecting} \mathrm{data.} \mathrm{In} \mathrm{Cochrane} \mathrm{Handbook} \mathrm{for}$ Systematic Reviews of Interventions Version 6.0 (Updated July 2019) (eds JPT Higgins, J Thomas, J Chandler, M Cumpston, T Li, MJ Page, et al.. Cochrane, 2019 (www.training.cochrane.org/handbook)

31 Deeks JJ, Higgins JPT, Altman DG. Analysing data and undertaking meta-analyses. In Cochrane Handbook for Systematic Reviews of Intervention Version 6.0 (Updated July 2019) (JPT Higgins, J Thomas, J Chandler, M Cumpston, T Li, MJ Page, et al.. Cochrane, 2019 (www.training.cochrane.org/ handbook).

32 Cochrane Training Centre. Review Manager 5 (RevMan 5), version 5.3 Cochrane, 2014

33 Sterne JAC, Savović J, Page MJ, Elbers RG, Blencowe NS, Boutron I, et al. RoB 2: a revised tool for assessing risk of bias in randomised trials. BMJ 2019; 366 : 14898.

34 Scottish Intercollegiate Guidelines Network. SIGN 50: A Guideline Developer's Handbook. SIGN, 2008

35 Shea BJ, Reeves BC, Wells G, Thuku M, Hamel C, Moran J, et al. AMSTAR 2: critical appraisal tool for systematic reviews that include randomised or nonrandomised studies of healthcare interventions, or both. BMJ 2017 Sep; 358 j4008.

36 Deb S, Cowie VA, Richens A. Folate metabolism and problem behaviour in mentally handicapped epileptics. J Intellect Disabil Res 1987; 31: 163-8.

37 Espie CA, Pashley AS, Bonham KG, Sourindhrin I, O'donovan M. The mentally handicapped person with epilepsy: a comparative study investigating psychosocial functioning. J Intellect Disabil Res 1989; 33: 123-35.

38 Gillies JB, Espie CA, Montgomery JM. The social and behavioural functioning of people with mental handicaps attending Adult Training Centres: a comparison of those with and without epilepsy. Mental Handicap Res 1989; 2: 129-36.

39 Collacott RA. Epilepsy, dementia and adaptive behaviour in Down's syndrome. J Intellect Disabil Res 1993; 37: 153-60.

40 Deb S. Mental disorder in adults with mental retardation and epilepsy. Compr Psychiatry 1997; 38: 179-84.
41 Matson JL, Bamburg JW, Mayville EA, Khan I. Seizure disorders in people with intellectual disability: an analysis of differences in social functioning, adaptive functioning and maladaptive behaviours. J Intellect Disabil Res 1999; 43: $531-9$.

42 Chung MC, Cassidy G. A preliminary report on the relationship between challenging behaviour and epilepsy in learning disability. Eur J Psychiatry 2001; 15: $23-32$

43 Matthews $\mathrm{T}$, weston $\mathrm{N}$, Baxter $\mathrm{H}$, Felce $\mathrm{D}$, Kerr M. A general practice-based prevalence study of epilepsy among adults with intellectual disabilities and of its association with psychiatric disorder, behaviour disturbance and carer stress. J Intellect Disabil Res 2008; 52: 163-73.

44 Smith KR, Matson JL. Psychopathology: differences among adults with intellectually disabled, comorbid autism spectrum disorders and epilepsy. Res Dev Disabil 2010; 31: 743-9.

45 Prasher VP. Epilepsy and associated effects on adaptive behaviour in adults with Down syndrome. Seizure 1995; 4: 53-6.

46 Espie CA, Watkins J, Curtice L, Espie A, Duncan R, Ryan JA, et al Psychopathology in people with epilepsy and intellectual disability; an investigation of potential explanatory variables. J Neurol Neurosurg Psychiatry 2003; 74: 1485-92.

47 Turkistani IY. Epilepsy in learning disabilities: relevance and association with mental illness and behavioural disturbances. J Learn Disabil 2004; 8: 89-99.

48 McGrother CW, Bhaumik S, Thorp CF, Hauck A, Branford D, Watson JM. Epilepsy in adults with intellectual disabilities: prevalence, associations and service implications. Seizure 2006; 15: 376-86.

49 Pawar DG, Akuffo EO. Comparative survey of comorbidities in people with learning disability with and without epilepsy. Psychiatr Bull 2008; 32: 224-6.

50 Fitzgerald ME, Matson JL, Barker A. Symptoms of psychopathology in adults with intellectual disability and seizures. Res Dev Disabil 2011; 32: 2263-6.

51 O'Dwyer C, McCallion P, Burke É, Carroll R, O'Dwyer M, McCarron M. Prevalence and associated factors of problem behaviours among older adults with intellectual disabilities in Ireland. Res Dev Disabil 2018; 80: 192-204.

52 Folch A, Cortés MJ, Salvador-Carulla L, Vicens $P$, Irazábal M, Muñoz S, et al. Risk factors and topographies for self-injurious behaviour in a sample of adults with intellectual developmental disorders. J Intellect Disabil Res 2018; 62: 1018-29.

53 Blickwedel J, Vickerstaff V, Walker M, Hassiotis A. Challenging behaviour, epilepsy and intellectual disability: a secondary analysis of findings from a randomised controlled trial. J Intellect Dev Disabil 2019; 44: 457-63.

54 Creaby $\mathrm{M}$, Warner $\mathrm{M}$, Jamil $\mathrm{N}$, Jawad $\mathrm{S}$. Ictal aggression in severely mentally handicapped people. Ir J Psychol Med 1993; 10: 12-5.

55 Deb S, Joyce J. Psychiatric illness and behavioural problems in adults with learning disability and epilepsy. Behav Neurol 1999; 11: 125-9.

56 Deb S, Joyce J. The use of antiepileptic medication in a population-based cohort of adults with learning disability and epilepsy. Int J Psychiatry Clin Pract 1999; 3 : 129-33.

57 Ring H, Zia A, Lindeman S, Himlok K. Interactions between seizure frequency, psychopathology, and severity of intellectual disability in a population with epilepsy and a learning disability. Epilepsy Behav 2007; 11: 92-7.

58 Collacott RA, Cooper S-A, Branford D, McGrother C. Epidemiology of self-injurious behaviour in adults with learning disabilities. Br J Psychiatry 1998; 173: 428-32.

59 Tyrer F, McGrother CW, Thorp CF, Donaldson M, Bhaumik S, Watson JM, et al. Physical aggression towards others in adults with learning disabilities: prevalence and associated factors. J Intellect Disabil Res 2006; 50: 295-304.

60 Holmes N, Shah A, Wing L. The Disability Assessment Schedule: a brief screening device for use with the mentally retarded. Psychol Med 1982; 12: 879-90.

61 Deb S, Hunter D. Psychopathology of people with mental handicap and epilepsy I: maladaptive behaviour. Br J Psychiatry 1991; 159: 822-6.

62 Deb S. Electrophysiological correlates of psychopathology in individuals with mental retardation and epilepsy. J Intellect Disabil Res 1995; 39: 129-35.

63 Wing L. Profile of Abilities and Adjustment. MRC Social Psychiatry Unit, Institute of Psychiatry, 1983

64 Nihira K, Foster R, Shellhaas M, Leland H. AAMD Adaptive Behavior Scale (1974 Rev.). American Association on Mental Deficiency, 1974.

65 Matson JL, Gardner WI, Coe DA, Sovner R. A scale for evaluating emotional disorders in severely and profoundly mentally retarded persons: development of the Diagnostic Assessment for the Severely Handicapped (DASH) scale. $\mathrm{Br} J$ Psychiatry 1991; 159: 404-9.

66 Aman MG, Burrow WH, Wolford PL. The Aberrant Behavior ChecklistCommunity: factor validity and effect of subject variables for adults in group homes. Am J Ment Retard 1995; 100: 283-92.

67 Andrews TM, Everitt AD, Sander JW. A descriptive survey of long-term residents with epilepsy and intellectual disability at the Chalfont Centre: is there a 
relationship between maladaptive behaviour and magnetic resonance imaging findings? J Intellect Disabil Res 1999; 43: 475-83.

68 Aman MG, Singh NN. Aberrant Behavior Checklist Manual (2nd edn). Slosson Educational Publications, 2017.

69 Espie CA, Gillies JB, Montgomery JM. Antiepileptic polypharmacy, psychosocial behaviour and locus of control orientation among mentally handicapped adults living in the community. J Intellect Disabil Res 1990; 34: 351-60.

70 Espie CA, Montgomery JM, Gillies JB. The development of a psychosocial behaviour scale for the assessment of mentally handicapped people. J Intellect Disabil Res 1988; 32: 395-403.

71 Rojahn J, Matson JL, Lott D, Esbensen AJ, Smalls Y. The Behavior Problems Inventory: an instrument for the assessment of self-injury, stereotyped behavior, and aggression/destruction in individuals with developmental disabilities. J Autism Develop Disorder 2001; 31: 577-88.

72 van Ool JS, Snoeijen-Schouwenaars FM, Tan IY, Schelhaas HJ, Aldenkamp AP Hendriksen JG. Challenging behavior in adults with epilepsy and intellectual disability: an analysis of epilepsy characteristics. Epilepsy Behav 2018; 86: 72-8.

73 Cooper SA, Smiley E, Allan LM, Jackson A, Finlayson J, Mantry D, et al. Adults with intellectual disabilities: prevalence, incidence and remission of self-injurious behaviour, and related factors. J Intellect Disabil Res 2009; 53: 200-16.

74 Cooper SA, Smiley E, Jackson A, Finlayson J, Allan L, Mantry D, et al. Adults with intellectual disabilities: prevalence, incidence and remission of aggressive behaviour and related factors. J Intellect Disabil Res 2009; 53: 217-32.

75 Royal College of Psychiatrists. DC-LD (Diagnostic Criteria for Psychiatric Disorders for Use with Adults with Learning Disabilities/Mental Retardation): 128. Gaskell Press, 2001

76 Matson JL, Terlonge C, González ML. Autism Spectrum Disorders-ComorbidityAdult Version. Disability Consultants, 2006

77 Smith KR, Matson JL. Behavior problems: differences among intellectually disabled adults with co-morbid autism spectrum disorders and epilepsy. Res Dev Disabil 2010; 31: 1062-9.

78 Matson JL, Rivet TT. Reliability and factor structure of the Autism Spectrum Disorders Behavior Problems for Adults (ASD-BPA) with intellectual disabilities and autism. J Ment Health Res Intellect Disabil 2008; 1: 34-47.

79 Coolican H. Research Methods and Statistics in Psychology. Psychology Press, 2017.

80 Egger M, Smith GD, Schneider M, Minder C. Bias in meta-analysis detected by a simple, graphical test. BMJ 1997; 315: 629-34.
81 Deb S. Self-injurious behaviour as part of genetic syndromes. Br J Psychiatry 1998; 172: 385-8.

82 Ratey JJ, Gutheil CM. The measurement of aggressive behaviour: reflections on the use of the Overt Aggression Scale and the Modified Overt Aggression Scale. J Neuropsych 1991; 3: 557-60.

83 Tellenbach $\mathrm{H}$. Epilepsie als Anfallsleiden und als Psychose-Uber alternative Psychosen paranoider Pragung bei "forcierter Normalizierung" (Landolt) des Elektoencephalogramms Epileptischer. Der Nervenarzt 1965; 36: 190-202.

84 Landolt $\mathrm{H}$. Some clinical electroencephalographical correlations in epileptic psychosis. Electroencephalogr Clin Neurophysiol 1953; 5: 121.

85 Goodwin GM, Haddad PM, Ferrier IN, Aronson JK, Barnes TR, Cipriani A, et al. Evidence-based guidelines for treating bipolar disorder: revised third edition recommendations from the British Association for Psychopharmacology. $J$ Psychopharmacol 2016; 30: 495-553.

86 Brodie MJ, Besag F, Ettinger AB, Mula M, Gobbi G, Comai S, et al. Epilepsy, antiepileptic drugs, and aggression: an evidence-based review. Pharmacol Rev 2016; 68: 563-602.

87 Deb S, Saini STK. Levetiracetam for the treatment of epilepsy among adults with intellectual disabilities. J Intel Disabil Res 2007; 51: 564-5.

88 National Institute for health and Care Excellence. The Epilepsies: The Diagnosis and Management of the Epilepsies in Adults and Children in Primary and Secondary Care (NICE Clinical Guideline CG137). NICE, 2012.

89 Deb S. Psychopharmacology. In Handbook of Evidence-Based Practices in Intellectual and Developmental Disabilities (ed NN Singh): 347-81. Springer International Publishing, 2016.

90 Young C, Shankar R, Palmer J, Craig J, Hargreaves C, McLean B, et al. Does intellectual disability increase sudden unexpected death in epilepsy (SUDEP) risk? Seizure 2015; 25: 112-6.

91 Einarsdottir AB, Sveinsson O, Olafsson E. Sudden unexpected death in epilepsy: a nationwide population-based study. Epilepsia 2019; 60: 2174-81.

92 Devinsky O. Sudden, unexpected death in epilepsy. N Engl J Med 2011; 365: 1801-11.

93 NHS England, NHS Improvement. Learning Disability Mortality Review (LeDeR) Programme: Action from Learning. NHS England, 2019. 